\title{
SOVEREIGN DEBT MARKETS IN TURBULENT TIMES: CREDITOR DISCRIMINATION AND CROWDING-OUT EFFECTS
}

\author{
Fernando Broner \\ Aitor Erce \\ Alberto Martin \\ Jaume Ventura \\ Working Paper 19676 \\ http://www.nber.org/papers/w19676 \\ NATIONAL BUREAU OF ECONOMIC RESEARCH \\ 1050 Massachusetts Avenue \\ Cambridge, MA 02138 \\ November 2013
}

We acknowledge financial support from the Spanish Ministry of Science and Innovation, the Spanish Ministry of Economy and Competitiveness Severo Ochoa Program, the Generalitat de Catalunya, and the European Research Council (Starting Grant FP7-263846 and Advanced Grant FP7-249588) for financial support. The views expressed herein are those of the authors and do not necessarily reflect the views of the European Stability Mechanism or the National Bureau of Economic Research.

NBER working papers are circulated for discussion and comment purposes. They have not been peerreviewed or been subject to the review by the NBER Board of Directors that accompanies official NBER publications.

(C) 2013 by Fernando Broner, Aitor Erce, Alberto Martin, and Jaume Ventura. All rights reserved. Short sections of text, not to exceed two paragraphs, may be quoted without explicit permission provided that full credit, including (C) notice, is given to the source. 
Sovereign Debt Markets in Turbulent Times: Creditor Discrimination and Crowding-Out Effects Fernando Broner, Aitor Erce, Alberto Martin, and Jaume Ventura

NBER Working Paper No. 19676

November 2013

JEL No. F32,F34,F36,F41,F43,F44,F65,G15

\begin{abstract}
$\underline{\text { ABSTRACT }}$
In 2007, countries in the euro periphery were enjoying stable growth, low deficits, and low spreads. Then the financial crisis erupted and pushed them into deep recessions, raising their deficits and debt levels. By 2010, they were facing severe debt problems. Spreads increased and, surprisingly, so did the share of the debt held by domestic creditors. Credit was reallocated from the private to the public sectors, reducing investment and deepening the recessions even further. To account for these facts, we propose a simple model of sovereign risk in which debt can be traded in secondary markets. The model has two key ingredients: creditor discrimination and crowding-out effects. Creditor discrimination arises because, in turbulent times, sovereign debt offers a higher expected return to domestic creditors than to foreign ones. This provides incentives for domestic purchases of debt. Crowding-out effects arise because private borrowing is limited by financial frictions. This implies that domestic debt purchases displace productive investment. The model shows that these purchases reduce growth and welfare, and may lead to self-fulfilling crises. It also shows how crowding-out effects can be transmitted to other countries in the euro zone, and how they may be addressed by policies at the European level.
\end{abstract}

Fernando Broner

CREI,

Universitat Pompeu Fabra

Ramon Trias Fargas, 25-27

08005 Barcelona

Spain

and Barcelona GSE

fbroner@crei.cat

Aitor Erce

European Stability Mechanism

43, Avenue John F.Kennedy

1855 Luxembourg

a.erce@esm.europa.eu

\author{
Alberto Martin \\ CREI, \\ Universitat Pompeu Fabra \\ Ramon Trias Fargas, 25-27 \\ 08005 Barcelona \\ Spain \\ and Barcelona GSE \\ amartin@crei.cat \\ Jaume Ventura \\ CREI, \\ Universitat Pompeu Fabra \\ Ramon Trias Fargas, 25-27 \\ 08005-Barcelona \\ SPAIN \\ and Barcelona GSE \\ and also NBER \\ jventura@crei.cat
}


In 2007 Greece, Ireland, Italy, Portugal, and Spain -or 'GIIPS'- were enjoying stable growth, their fiscal deficits were low, their public debts were not particularly large and their sovereign spreads were close to zero. ${ }^{1}$ The financial crisis that erupted in the summer of 2007 pushed these economies, as it did many others around the world, into deep recessions. Figure 1 shows how this affected these countries' sovereign debts. During 2008 and 2009, a combination of low growth and large budget deficits led to rapidly increasing debt-to-GDP ratios. This did not seem worrisome at the time, though, as financial markets absorbed this additional debt as they had done in the past. Until late 2009, average spreads were still low and the share of sovereign debt in the hands of domestic residents was below 50\% in all GIIPS, and even below $30 \%$ in Ireland and Greece.

The situation deteriorated sharply at the end of 2009, leading to severe sovereign debt problems in 2010. One piece of bad news was that some of the GIIPS, such as Ireland or Spain, reported much larger budget deficits than previously anticipated. But the most striking development, took place in Greece, where the new government revised the fiscal accounts for previous years and found deficits much larger than previously reported. This discovery generated a loss of confidence on the fiscal constraints under which Euro countries were supposed to operate.

These events did not slow down the growth of debt, but they did affect how it was absorbed by markets. This is also shown in Figure 1. Spreads started to rise sharply and, by the end of 2012, all GIIPS had spreads within 400 and 800 basis points, with the exception of Greece whose spread was much higher. A more surprising development is that the share of debt held by these countries' private sectors increased alongside spreads. By the end of 2012, this share was above $50 \%$ in all GIIPS, and even above $70 \%$ in Spain and $60 \%$ in Italy. ${ }^{2}$ Contrary to the standard logic of optimal diversification, private sectors in GIIPS bought a lot of sovereign debt precisely as it became riskier and more correlated with domestic outcomes. As this appetite for debt grew, credit was reallocated from the private to the public sectors, reducing investment and deepening the recessions even further.

Soon these difficulties became too large to be handled domestically, and help from abroad came in a variety of ways. It all started with the approval of official support packages crafted in the style of standard International Monetary Fund (IMF) programs. Greece received a first

\footnotetext{
${ }^{1}$ Of course, there was more heterogeneity among GIIPS' economies than this description suggests. In particular, Portugal and Italy were growing more slowly, Portugal and Greece had larger deficits, and Italy and Greece had larger public debts.

${ }^{2}$ Brutti and Sauré (2013) have emphasized this aspect of the crisis and carefully documented it. Arslanalp and Tsuda (2012) and Merler and Pisani-Ferry (2012) have also noticed this pattern. More generally, Broner et al. (2013) show that periods of financial turbulence are often accompanied by a reduction in gross capital flows, in which foreigners reduce their purchases of domestic assets and domestic residents reduce their purchases of foreign assets.
} 
loan of 110 bn euros in May 2010 and an additional 130 bn euros in March 2012. The first loan was articulated through bilateral agreements with euro area countries and an IMF program. The second was financed jointly by the IMF and the European Financial Stability Fund (EFSF), the first euro-zone institutional mechanism designed to jointly support distressed euro sovereigns. In turn, Ireland received a loan of 67.5 bn euros in November 2010 and Portugal a loan of 78 bn euros in April 2011, both also jointly financed by the IMF and the EFSF. As the crisis deepened the euro zone decided to equip itself with a permanent crisis resolution institution, the European Stability Mechanism (ESM). So far, the ESM has provided financing for the cleaning up of the financial system in Spain in late 2012 and contributed most of the funding for the recently signed Cypriot package. An important additional form of support came through the various measures taken by the European Central Bank (ECB), most notably the Securities Markets Program (SMP) for purchases of distressed sovereign bonds in secondary markets. ${ }^{3}$

Despite these efforts by their European partners, at the time of writing, GIIPS are still far from solving their sovereign debt problems. This is so despite painful fiscal adjustments and considerable efforts at implementing economic reforms. Even worse, there is still widespread disagreement about the underlying causes and potential remedies of this situation. Why have sovereign spreads increased so much? Why, in the midst of a deep recession, have the private sectors of GIIPS purchased the debts of their sovereigns? What are the economic consequences of these purchases? What are the key inefficiencies that they generate? What is the right set of policies to address them? What difference does it make that GIIPS belong to the European Union? Is there a role for Europe-wide policy?

The goal of this paper is to provide an analytical perspective on these issues. ${ }^{4}$ We propose a theory with two key ingredients: creditor discrimination and crowding-out effects. By creditor discrimination we mean that, in turbulent times, sovereign debt offers a higher expected return to domestic creditors than to foreign ones. This happens in part because domestic creditors are less likely to be defaulted on by their governments. ${ }^{5}$ It could also happen because of the plethora of

\footnotetext{
${ }^{3}$ Additionally, the ECB has modified its collateral rules to accept lower rated sovereign debt, provided liquidity through the Long-Term Repurchase Operations (LTRO), and even announced (on August 2012) the possibility of purchasing unlimited amounts of sovereign securities through Outright Monetary Transactions (OMT).

${ }^{4}$ Our narrative has been, per force, short and focused on the elements that we emphasize later in the theory. See Ardagna and Caselli (2012), Lane (2012), and Shambaugh (2012) for detailed and very useful descriptions of the European sovereign debt crisis. See also the many references therein for further details. Bolton and Jeanne (2011), Catão et al. (2012), Roch and Uhlig (2012), and Conesa and Kehoe (2013) also use formal models to study this episode.

${ }^{5}$ Sturzenegger and Zettelmeyer (2007), Cruces and Trebesch (forthcoming), and Erce (2012 and forthcoming) document the existence of breaches in inter-creditor equity during sovereign defaults, and that domestic residents are
} 
ad-hoc domestic regulations imposed during these turbulent periods which tend to have a larger impact on domestic than foreign creditors. Whatever its origin, though, discrimination provides incentives for domestic purchases of debt. If private credit markets worked perfectly, the purchases of sovereign debt by domestic creditors could be financed by borrowing from foreign creditors. But private borrowing is limited by financial frictions. As a result, purchases of sovereign debt by domestic creditors displace productive investment. This is the crowding-out effect. Combined, these two ingredients imply that these debt purchases are welfare-reducing. Even though creditors might benefit from the high returns of domestic debt, the economy as a whole loses because of the foregone investment opportunities.

We organize the rest of the paper in five sections. In Section 1, we document a number of stylized facts for GIIPS, using France and Germany as a comparison group. As mentioned already, debt-to-GDP ratios have increased substantially since 2008, while spreads started to grow only after 2010. We first decompose changes in debt-to-GDP ratios into various components and find that their growth in GIIPS can be explained to an important extent by the deep recessions and high interest rates they face since 2010. Then, we look at two characteristics of this debt. The first one is its maturity structure, which has been stable and long term throughout the period. The second is the identity of the debt holders which, as mentioned already, shifted from foreign to domestic after 2010. Finally, we examine how domestic credit markets were affected during the period. We find that not much happened until 2009. Starting in 2010, however, there was a marked reallocation of credit from the private to the public sector. Also, the borrowing costs for the domestic private sector increased substantially, mimicking those of the sovereign. These developments suggest that crowding-out effects are playing an important role in the European sovereign debt crisis.

In Sections 2 and 3, we develop the theory using a small open economy version of the Diamond model with credit frictions. Without discrimination, this model features a concave law of motion with standard convergence dynamics and a single steady state. Sovereign debt has no effect on investment and growth. With discrimination, however, the law of motion becomes convex for a range of capital stocks leading to nonstandard dynamics and the possibility of multiple steady states. Within this range, sovereign debt crowds out investment and lowers growth. The size and shape of this "crowding-out region" depends on the stock of debt and the probability of default. While some economies might eventually outgrow the crowding-out region and reach an equilibrium

more likely to be treated preferentially. Erce (2012) points to three additional determinants of discrimination: the composition of debt, the health and size of the financial sector, and the private sector's reliance on external sources of finance. 
with high output, others may be permanently trapped in equilibria with low investment and output. We study the efficiency properties of these equilibria and discuss the type of policies that are needed to reduce the crowding-out region and avoid low-output equilibria.

In Section 4, we use the model to show how discrimination can also lead to self-fulfilling crises. The key additional assumption is that default penalties increase with the economy's capital stock or output. ${ }^{6,7}$ If the probability of default is expected to be low, foreign creditors purchase the debt, investment and growth are high, and the probability of default is low. If the probability of default is expected to be high, domestic creditors purchase the debt, investment and growth are low and the probability of default is high. These self-fulfilling crises are possible in a subset of the crowding-out region, which we label the crisis zone. Within this zone, crowding-out effects are essentially random and depend on expectations. Some economies remain indefinitely trapped within the crisis zone, with permanent volatility driven by changes in expectations. Others experience these crises only as temporary phenomena and eventually leave the crisis zone. They can do so from above and reach a high level of investment and output, or from below and converge to a low level of investment and output. The presence of multiple equilibria adds another dimension to policy design. In particular, there might be policies that, without altering the crowding-out region, might still be helpful in coordinating the economy to the optimistic equilibrium.

In Section 5, we extend the model to the case of an economic union. This is meant to capture the increasingly important role that euro-zone institutions, such as the official rescue mechanisms (ESM/EFSF) and the ECB, are playing in the evolution of GIIPS' economies and in the market for their sovereign debts. The key additional assumption is that creditor discrimination is relatively low within a union. This creates a union-wide market for the debt issued by any of the member countries, through which crowding-out effects are effectively 'exported' to the rest of the union. Conversely, if there is an increase in the probability of a union break up, debt flows back to the originating countries, concentrating the crowding-out effects and fostering divergence within the union. We use this extension of the model to explore the role of union-wide policies in reducing the strength of crowding-out effects.

In Section 6, we go back to the questions raised above and show how the theory helps providing tentative answers. Before going through this plan, though, we offer a short review of related

\footnotetext{
${ }^{6}$ The assumption that the loss imposed by creditors is increasing in the size of the economy is standard in the literature. This would be the case if, for example, defaults lead to lower productivity or, in a richer model, an increase in the cost of trading goods with foreigners.

${ }^{7}$ Consistent with the evidence presented by Cruces and Trebesch (forthcoming), we assume that penalties are increasing in the size of the default.
} 
literature.

\section{LITERATURE REVIEW:}

Our paper is part of a growing literature that emphasizes the role of secondary markets in enforcing debts. This work has so far focused on how secondary markets restrict the actions of governments ex post, i.e. close to maturity or after defaults. Close to maturity, Broner et al. (2010) show that secondary markets both reduce the probability of default on foreigners and make it difficult for governments to discriminate among creditors. Guembel and Sussman (2009), Broner and Ventura (2010 and 2011), Brutti (2011), and Gennaioli et al. (forthcoming) show that this inability to discriminate increases the probability of both repayment to foreigners and default on domestic residents. After default, secondary markets raise the bargaining power of creditors and reduce inefficiencies. For instance, Lanau (2011) shows that renegotiations lead to smaller haircuts when debts can be sold to those agents that can extract more repayment. Pitchford and Wright (forthcoming) show that secondary markets can increase repayment by concentrating debts on the optimal number of creditors. Bai and Zhang (2012) show that secondary markets can reduce delay by providing information on creditors' reservation values. In all these cases, since governments face a time inconsistency problem, the constraints imposed on them ex post by secondary markets can be either beneficial or damaging from an ex ante point of view.

Here we focus instead on how secondary markets restrict the actions of governments ex ante, i.e. far from maturity. We model a situation in which secondary markets are open now but might fail to be open in the future, for example due to capital controls. This creates an expectation of discrimination that leads foreigners to sell their non-maturing debts to domestic residents. These purchases of government debt by domestic residents crowd out investment, reduce growth, and can increase the probability of default. In this case secondary markets also constraint the actions of governments. In particular, secondary markets make it difficult for governments to segment domestic and foreign markets when debts are issued and to control the retrading of non-maturing debts. If we assume that governments are benevolent, these ex-ante constraints are damaging to welfare.

Our paper is also related to a recent literature that analyzes how sovereign defaults affect private investment and growth. One set of papers, Aguiar et al. (2009) and Aguiar and Amador (2011), show that high levels of public debt can reduce private investment and growth by increasing governments' incentives to default and expropriate private capital. As in our model, in these papers 
investment is affected by the size of government debt. But the allocation of debt between foreign and domestic creditors and the potential for crowding out play no role in the mechanism. Another set of papers, Brutti (2011), Erce (2012), Mendoza and Yue (2012), Mengus (2012), and Gennaioli et al. (forthcoming), show that sovereign defaults can reduce investment and growth due to their effects on private balance sheets and borrowing limits. Unlike our model, in these papers growth is not reduced by the accumulation of debts in domestic hands as risk increases, but rather by the actual realization of defaults. So these papers' implications for the timing of events is very different from ours.

Finally, our paper is related to the literature on self-fulfilling debt crises, notably Calvo (1988), Cole and Kehoe (2000), Corsetti and Dedola (2012), Aguiar et al. (2013), Conesa and Kehoe (2013), and Lorenzoni and Werning (2013). Like us, these papers show that crises can be triggered by creditors becoming pessimistic and, thus, either refusing to buy the debt or demanding very high interest rates. However, the mechanism in these papers is different from ours. For example, a key message of this literature is that lengthening the maturity structure reduces countries' vulnerability to self-fulfilling debt crises. The reason is that the longer the maturity the smaller the payments countries must make if the debt cannot be refinanced, i.e. the smaller the potential "run" by foreigners. In our model, however, this is not the case because secondary markets allow foreigners to sell non-maturing debts to domestic residents. As a result, the potential run by foreigners is not reduced by a longer maturity. Instead, the degree of discrimination is what determines the potential crowding out and, thus, whether the pessimistic equilibrium exists.

\section{A bird's-eye view of the European debt crisis}

In this section, we present six stylized facts about the European sovereign debt crisis. We focus on five "periphery" countries, Greece, Ireland, Italy, Portugal, and Spain, or GIIPS. We contrast their performance with that of two "core" countries, Germany and France. Appendix 4 provides a detailed description of our data sources.

1.DEBT AND SPREADS: Debt-to-GDP ratios have been increasing fast in GIIPS since 2008. But spreads remained low through 2009 and increased sharply in 2010.

This has already been shown in Figure 1 of the introduction. The most notable feature of this figure is the delay between the increase in debt-to-GDP ratios and the increase in sovereign spreads. 
2. DEBT DYNAMICS: The increase in debt-to-GDP ratios in GIIPS have been due to a large extent to the deep recessions and high interest rates these countries are facing.

We can decompose the changes in debt-to-GDP ratios into growth, interest-rate, and deficit components using the following identity:

$$
\triangle d_{t}=-\frac{g_{t} \cdot d_{t-1}}{1+g_{t}}+\frac{i_{t} \cdot d_{t-1}}{1+g_{t}}+\text { deficit }_{t}
$$

where $d_{t}$ is the debt-to-GDP ratio, $g_{t}$ is the growth rate of nominal GDP, $i_{t}$ is the nominal interest

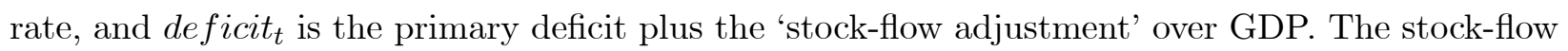
adjustment takes into account operations that affect the level of debt but not the deficit. ${ }^{8,9}$

Figure 2 presents the average changes in debt-to-GDP ratios and the average growth, interestrate, and deficit components over three time periods. The first period runs from 2000 to 2007 and it describes debt dynamics before the crisis. The second period runs from 2008 to 2009, or the peak of the global financial crisis. The third period runs from 2010 to 2012 and it shows debt dynamics once GIIPS started facing severe debt pressures.

It is clear that the drivers of debt accumulation in GIIPS and in Germany and France have been very different. In the run up to the crisis, growth was particularly important in helping to reduce debt-to-GDP ratios in GIIPS, and to a lesser extent in Germany and France. There was heterogeneity in deficits, but on average they were not higher in GIIPS than in Germany and France. The debt dynamics during the global financial crisis were similar in both groups of countries, with negative growth and large deficits contributing to increase their debt-to-GDP ratios. Since 2010, deficits have remained high in most countries. ${ }^{10}$ But while the growth component has helped reduce debt-to-GDP ratios in Germany and France, this has not been the case in GIIPS, and in Greece negative growth has been the most important factor explaining its increase in debt-to-GDP ratio. In addition, very low interest rates in Germany and France have helped keep their interest-rate

\footnotetext{
${ }^{8}$ Examples of such operations include governments borrowing to finance bank recapitalization programs or privatizations. In these cases there is a change in gross assets and liabilities but not in net assets so that it does not appear in official deficit statistics. In the case of bank recapitalizations, if and when losses are realized they will affect the deficit.

${ }^{9}$ The data on government finances comes from the OECD's Economic Outlook Database and the data on nominal GDP from Eurostat.

${ }^{10}$ Our measure of deficit includes a variety of factors that partially obscures its interpretation. First, a decomposition of deficit into structural and cyclical (using OECD data) shows that GIIPS' high deficits are almost solely explained by their cyclical component, reinforcing our observation that debt dynamics are driven by the deep recessions they face. In fact, fiscal austerity in these countries has eliminated their structural deficits by now. Second, the very low deficit in Greece reflects the reduction in debt due to its restructuring. Third, our measure of deficits have been especially large due stock-flow adjustments in those countries that spent substantial resources recapitalizing their banks.
} 
component from increasing despite higher debts. But the high interest rates GIIPS are facing have increased the interest-rate component in these countries and will continue to do so in the future since these high rates have been locked into their long-term debt. Overall, relative to Germany and France the debt-to-GDP ratios in GIIPS have increased as a result of deep recessions and high borrowing costs they face since 2010 .

3. DEBT MATURITY: The sovereign debt maturity structure in GIIPS has been stable, long term, and quite similar to that in Germany and France.

We have compiled information on the maturity structure of sovereign debt from various sources. ${ }^{11}$ The top panel of Figure 3 shows that, since the inception of the euro, GIIPS have increased their average debt maturity. By 2007, they had brought it in line with the average maturity in France and Germany, at around five-seven years. As a result, when the crisis hit there was no significant difference in debt maturity between GIIPS and Germany and France. Average maturity fell temporarily to four years in Ireland in 2008, and it has increased markedly in Greece after its debt restructuring.

The bottom panel of Figure 3 shows the fraction of sovereign debt that is short term, or due in less than one year. Short-term debt has more variation across countries than average maturity. But GIIPS have actually less short-term debt than France and Germany, with the exception of Ireland in 2008.

4. DEBT HOLDINGS: As sovereign spreads increased, sovereign debt holdings shifted from foreign to domestic residents in GIIPS. Among domestic residents, banks have played a major role but other domestic sectors have also increased their holdings of public debt.

We put together a dataset on sovereign debt holdings by foreign private, foreign official, domestic financial, domestic non-financial and domestic public sectors. We used some of the data in Andritzky (2013) and Merler and Pisani-Ferry (2012), replacing their series that were at market prices with updated face-value data from national sources. ${ }^{12,13}$

\footnotetext{
${ }^{11}$ The data on average maturity is from the ECB, the OECD, and the Spanish Ministry of finance. The data on short-term debt is from the ECB, the Irish Central Bank, and the Spanish Ministry of Finance.

${ }^{12}$ National sources include Treasuries and Central Banks. For Greece the only data available mixes nominal and market prices. For France, the non-financial and public domestic sectors cannot be disentangled.

${ }^{13}$ Several recent papers have also analyzed the behavior of sovereign debt holdings for GIIPS, including IMF's Global Financial Stability Report (2011), Arslanalp and Tsuda (2013), and Brutti and Sauré (2013). These papers combine data from the IMF's International Financial Statistics on domestic sovereign debt holdings with data from the BIS on public debt holdings by non-resident banks. An advantage of these data sources is that the BIS data is bilateral. This allows Brutti and Sauré (2013) to analyze the differential behavior of banks within and outside
} 
Figure 4 shows the proportion of sovereign debt held by domestic residents and by foreigners, and also the corresponding 10-year country spreads. The figure clearly shows that the crisis marked a turning point in the behavior of domestic versus foreign debt holdings. Prior to the crisis, the proportion of sovereign debt in the hands of foreigners had been increasing for all countries but Portugal. As sovereign spreads rose, the share of debt in the hands of foreigners started decreasing. At the same time, domestic residents increased significantly their exposure to their own sovereign debt. This shift is clear in all GIIPS. Even in France there has been a small shift from foreign to domestic debt holders, coinciding with a smaller increase in spreads. Instead, in Germany the fraction of sovereign debt held by foreigners has kept increasing throughout the crisis.

Figure 5 shows the behavior of sovereign debt holdings by the non-financial and financial domestic private sectors and by foreigners. As foreigners decreased their debt holdings, domestic banks clearly increased their exposure to their sovereign's debt. But the non-financial sector also tended to increase its exposure in those countries in which they had held significant amounts of sovereign debt before the crisis. This is the case in Italy, Greece, Spain, and perhaps even in France. In Portugal, though, debt holdings by the non-financial sector continued trending down as before the crisis. Overall, although banks have played an important role in absorbing their countries' sovereign debt, other domestic sectors have not behaved too differently.

5. CREDIT ALLOCATION: Domestic credit has shifted from the private to the public sector in GIIPS. This shift has coincided in time with the rise in each country's corresponding sovereign spread.

To analyze the allocation of credit across domestic sectors, we collected information on the lending by domestic banks, either through loans or security holdings, to three sectors: general government, non-financial corporations, and households. ${ }^{14}$ Figure 6 shows bank credit as a fraction of GDP to these three sectors. The figure shows how until the onset of the crisis both households and corporations had received an increasing amount of credit in GIIPS. This pattern is most clear in Spain and Ireland, but is also present in Portugal, Italy and Greece. In France and Germany, instead, credit to households and corporations had remained stable, with the exception of credit to households in France starting in 2005. This behavior contrasts with that of public borrowing,

the euro area. A disadvantage of these data sources is that debt is valued at market prices, making it difficult to disentangle changes in portfolios due to trading and price changes. Arslanalp and Tsuda (2013) addressed this problem by converting the data back to face value using each country's reported valuation method.

${ }^{14}$ These data are from each country's Financial Accounts and from their National Central Banks' Monetary Surveys. We also use 10-year sovereign bond spreads from Datastream. 
which had barely increased and, for Spain and Germany, even presented a declining trend prior to the crisis. These patterns changed markedly after the onset of the crisis. Since then, in GIIPS credit to households and corporations stopped growing and, in Ireland, Portugal, and Spain, started contracting. At the same time, credit to the government increased sharply. In contrast, in Germany and France the crisis has had very little effect on credit to these three sectors.

Figure 7 shows the ratio of public credit (or credit to the government) to private credit (sum of credit to non-financial corporations and households) and 10-year sovereign spreads. ${ }^{15}$ In all GIIPS there has been a marked increase in the ratio of public to private credit since the beginning of the crisis, breaking earlier downward trends. This is not observed in Germany of France. ${ }^{16}$ Importantly, the timing of the start of the shift in the relative importance of public and private credit coincides precisely with the increase in sovereign spreads in each of the GIIPS. In France, where sovereign spreads have remained low, there is no such pattern.

6. BORROWING COSTS FOR PRIVATE SECTOR: As sovereign spreads increased in GIIPS, so did borrowing costs for the domestic private sector.

Figure 8 shows the behavior of private-sector and sovereign borrowing costs. For private-sector borrowing costs, we use corporate and consumer spreads, calculated as the difference between bank lending rates at 5-year horizons for both sectors and German 5-year sovereign rates. For sovereign borrowing costs we use sovereign spreads also at a 5-year horizon. The figure shows that as sovereign spreads started increasing in GIIPS in 2010, both corporate and consumer spreads started increasing as well. This suggests that the credit reallocation from the private to the public sectors pointed out above led to crowding out and more difficult access to credit for domestic firms and consumers.

These six stylized facts provide an interesting and somewhat puzzling account of recent events in Europe. In 2007 the economies of Greece, Ireland, Italy, Portugal, and Spain were growing fast, their fiscal deficits were low and their public debts were not particularly large. The 2008-2009 financial crisis changed this. It pushed each of the GIIPS into deep recessions with the result that budget deficits, together with falling GDP, led to higher and rapidly increasing debt-to-GDP ratios in these economies. Debt maturity however remained stable and long term.

\footnotetext{
${ }^{15}$ Since spreads are computed relative to German bonds, the spread is zero by definition for Germany.

${ }^{16}$ In Greece the ratio of public to private credit fell with the sovereign debt restructuring in 2012, but it has started to increase again since then. In Germany there was also an increase credit to the public in 2008 due to the need to recapitalize banks after the subprime crisis, but this was reversed soon afterwards.
} 
Something happened in early 2010 that caused severe sovereign debt problems. Perhaps fundamentals deteriorated or were revealed to be worse than expected. Perhaps there was a change in investor sentiment in a situation where multiple equilibria were possible. Whatever it was, it led to a substantial increase in sovereign spreads. Sovereign costs increased and recessions deepened even further, leading to further increases in debt-to-GDP ratios in GIIPS. In the midst of these developments, the private sectors of these countries began accumulating their own governments' debts. As the appetite for domestic debt grew there was a marked reallocation of credit from the private to the public sector, increasing borrowing costs for domestic firms and consumers. How can we make sense of these developments? The rest of the papers attempts to answer this question.

\section{A model of sovereign debt, investment and growth}

In this section we build on a small open economy version of the Diamond model to study the effects of sovereign debt on investment and growth. If foreign and domestic creditors are treated equally, this model features a concave law of motion with standard convergence dynamics and a single steady state. Sovereign debt has no effects on investment and growth. If there is discrimination against foreign creditors, however, the law of motion becomes convex for a range of capital stocks. Within this range, sovereign debt crowds out investment and lowers growth. The size and shape of this "crowding-out region" depends on the stock of debt and the probability of default.

\subsection{The baseline model}

Consider a country with a private sector that consists of generations that live for two periods. All generations have size one and contain a measure $\mu$ of patient individuals that maximize expected consumption during old age, and a measure $1-\mu$ of impatient individuals that maximize consumption during youth. Thus, the patient save all their youth income and invest these savings so as to maximize their expected return. The impatient consume all their income during youth.

All generations receive one unit of labor when young, which they supply inelastically. They have access to a Cobb-Douglas technology to produce goods: $F\left(l_{t}, k_{t}\right)=l_{t}^{1-\alpha} \cdot k_{t}^{\alpha}$; where $l_{t}$ is employment and $k_{t}$ is the capital stock and $\alpha \in(0,1)$. The production of one unit of capital in period $t+1$ requires the investment of one unit of the consumption good at time $t$. We assume that capital depreciates at a rate $\delta \in(0,1)$, and is reversible. Factor markets are competitive and, 
as a result, all available factors are employed and paid their marginal products:

$$
\begin{gathered}
w_{t}=(1-\alpha) \cdot k_{t}^{\alpha} \\
r_{t}=\alpha \cdot k_{t}^{\alpha-1}
\end{gathered}
$$

where $w_{t}$ and $r_{t}$ are the wage and the rental rate, respectively. Equations (2) and (3) already take into consideration that $l_{t}=1$ in equilibrium.

There is a risk-neutral international financial market willing to borrow or lend at a (gross) expected return of $\rho>1$. We refer to $\rho$ as the interest rate. Here we introduce the first friction: the private sector can pledge to its creditors only a return of $\phi<\rho$ per unit of investment. ${ }^{17}$ As a result, it faces the following credit constraint:

$$
f_{t} \leq \frac{\phi \cdot k_{t+1}}{\rho}
$$

where $f_{t}$ is the financing or credit that the private sector receives from the international financial market. Equation (4) says that this credit cannot exceed the net present value of pledgeable funds. Since these funds are known as of period $t$, the credit obtained by the private sector is riskless. If the credit constraint is not binding, the return to investment equals the rental rate plus the value of undepreciated capital, i.e. $r_{t+1}+1-\delta$. If the credit constraint is binding, the return to investment is higher since each unit of capital can be leveraged to further expand borrowing and investment, i.e. $\frac{\rho}{\rho-\phi} \cdot\left(r_{t+1}+1-\delta-\phi\right)$. Thus, for each unit of output invested $\frac{\rho}{\rho-\phi}$ units of capital are produced, and each of these units of capital delivers the rental rate plus the undepreciated capital minus the financing costs.

The law of motion of the capital stock is given by:

$$
k_{t+1}=\min \left\{\frac{\rho}{\rho-\phi} \cdot s \cdot k_{t}^{\alpha},\left(\frac{\alpha}{\rho+\delta-1}\right)^{\frac{1}{1-\alpha}}\right\}
$$

where $s \equiv \mu \cdot(1-\alpha)$ is the economy's gross saving rate and $k^{*} \equiv\left(\frac{\alpha}{\rho+\delta-1}\right)^{\frac{1}{1-\alpha}}$ is the unconstrained level of capital. Equation (5) has upward-sloping and horizontal sections, depicted as the solid line in Figure 9. The domestic private sector would like to invest until the return to

\footnotetext{
${ }^{17}$ For instance, the private sector cannot pledge future output, but it can pledge some undepreciated capital. Under this interpretation, we have that $\phi \in[0,1-\delta]$.
} 
investment equals the interest rate, i.e. until $k_{t+1}=k^{*}$. But this investment might be unattainable if the credit constraint binds. In this case, the private sector invests as much as possible and $k_{t+1}=\frac{\rho}{\rho-\phi} \cdot s \cdot k_{t}^{\alpha} \cdot{ }^{18}$ Since the law of motion is globally concave, this economy has a single steady state to which it converges monotonically.

\subsection{Sovereign debt, default and crowding-out effects}

We now introduce sovereign debt into the analysis. In particular, we consider a government that inherits an amount of debt $d_{t}$. The government can issue one-period bonds. Let $R_{t}$ be the gross contractual rate of one-period bonds issued at $t-1$. Let $x_{t}$ be the primary budget surplus, which equals the proceeds from consumption taxes minus (useless) government spending. ${ }^{19}$ With probability $p_{t} \leq 1$, the institutions of the country succeed in forcing the government to pay the debt. When institutions fail, the government defaults. We follow much of the literature on sovereign debt and assume that a default, either full or partial, leads to a permanent inability to issue new debt. This means that the primary budget surplus is zero from then onwards.

Thus, we can write the law of motion of the debt conditional on not having defaulted before period $t$ as follows:

$$
d_{t+1}= \begin{cases}R_{t} \cdot d_{t}-x_{t} & \text { with prob. } p_{t} \\ 0 & \text { with prob. } 1-p_{t}\end{cases}
$$

Equation (6) shows that the evolution of the debt depends on two key variables: (i) the size of the fiscal adjustment or effort, as measured by the primary budget surplus $x_{t}$; and (ii) the quality of institutions or credibility of the government, as measured by the probability of repayment $p_{t}$. These variables play a key role in what follows.

The effect on sovereign debt on the economy depends crucially on who purchases the debt. And this, in turn, depends on what happens when the government defaults on its debt. Consider first the case in which the government defaults on foreign and domestic creditors alike. In this case, the contractual interest rate on government debt is given by:

$$
R_{t+1}=\frac{\rho}{p_{t+1}}
$$

Equation (7) says that the spread on sovereign debt must compensate for default risk. With this

\footnotetext{
${ }^{18}$ When the constraint is binding, we have that $f_{t}=\frac{\phi \cdot k_{t+1}}{\rho}$ and $k_{t+1}=s \cdot k_{t}^{\alpha}+f_{t}$. Combining these observations, we find the maximum attainable investment.

${ }^{19}$ We only consider paths of $x_{t}$ that ensure that the debt never explodes.
} 
compensation, foreign and domestic creditors are indifferent between purchasing sovereign debt or lending in the international financial market. Interestingly, this implies that sovereign debt does not affect the law of motion in Equation (5), and, therefore, it does not affect investment and growth. If the return to investment exceeds $\rho$ and the credit constraint is binding, the domestic private sector devotes all its resources to investment and the debt is purchased entirely by foreigners. If the return to investment equals $\rho$ and the credit constraint is not binding, any purchase of sovereign debt by the domestic private sector replaces its lending to the rest of the world, and not investment. To be clear, the budget surplus and the probability of default determine the amount of debt that can be issued and welfare. But these variables have no impact on investment and growth. ${ }^{20}$

Consider next the case in which the government defaults on the debt held by foreign creditors, but it repays the debt held by domestic creditors. This creates a wedge between the expected return to holding debt by domestic and foreign creditors. In particular, the expected return for domestic and foreign creditors is $R_{t+1}$ and $R_{t+1} \cdot p_{t+1}$, respectively. Thus, the contractual interest rate on sovereign debt depends on the identity of the marginal buyer. If this is a foreign creditor, the contractual interest rate of debt must be such that this creditor is indifferent between purchasing sovereign debt or lending. If the marginal buyer of debt is a domestic creditor, however, purchasing sovereign debt always dominates lending and the contractual interest rate must be such that this creditor is indifferent between purchasing sovereign debt and investing. This implies that the contractual interest rate is given as follows:

$$
R_{t+1}=\min \left\{\frac{\rho}{p_{t+1}},\left(\alpha \cdot k_{t+1}^{\alpha-1}+1-\delta-\phi\right) \cdot \frac{\rho}{\rho-\phi}\right\}
$$

Equation (8) says that, if the return to investment exceeds the interest rate, the domestic private sector does not buy the debt and the marginal buyer is a foreign creditor. If instead the return to investment falls short of the contractual interest rate, the domestic private sector buys the debt and the marginal buyer is a domestic creditor.

This discussion suggests that the identity of the marginal buyer of debt, and hence the effects of debt on investment and growth, depends on the economy's capital stock. Indeed, we can write

\footnotetext{
${ }^{20}$ For instance, if $x_{t}=x$ and $p_{t}=p$, the maximum debt that the government can issue is $\frac{p}{\rho-p} \cdot x$. And the welfare of taxpayers declines by $x$. The path of $k_{t}$ is unaffected, though. This is due to our assumption that taxation does not affect investment. Appendix 1 relaxes this assumption and shows that this does not affect our main results, though.
} 
the law of motion of the capital stock as follows:

$$
k_{t+1}=k_{+1}\left(k_{t} ; p_{t+1}\right) \equiv \begin{cases}\min \left\{\frac{\rho}{\rho-\phi} \cdot s \cdot k_{t}^{\alpha},\left(\frac{\alpha}{(\rho-\phi) / p_{t+1}+\phi+\delta-1}\right)^{\frac{1}{1-\alpha}}\right\} & \text { if } k_{t}<\bar{k}_{t} \\ \min \left\{\frac{\rho}{\rho-\phi} \cdot\left(s \cdot k_{t}^{\alpha}-d_{t}\right), k^{*}\right\} & \text { if } k_{t} \geq \bar{k}_{t}\end{cases}
$$

where $\bar{k}_{t}$ is the capital stock at which the marginal buyer shifts from a foreign to a domestic creditor, and it is implicitly defined as follows:

$$
\frac{\rho}{\rho-\phi} \cdot\left(s \cdot \bar{k}_{t}^{\alpha}-d_{t}\right)=\left(\frac{\alpha}{(\rho-\phi) / p_{t+1}+\phi+\delta-1}\right)^{\frac{1}{1-\alpha}} .
$$

Equation (9) shows the law of motion of the capital stock when default affects only foreign creditors, and is depicted as the dashed line in Figure 9. Recall that the solid line depicts the law of motion when default affects foreign and domestic creditors alike, and coincides with $k_{+1}(\cdot ; 1)$.

The most noticeable aspect of this law of motion is the convex region in which the solid and dashed lines do not coincide. We refer to this region as the 'crowding-out region', because inside it sovereign debt crowds out investment and lowers growth. If $k_{t}<\bar{k}_{t}$, this crowding-out effect is only partial, as some of the debt is held by foreign creditors. If instead $k_{t} \geq \bar{k}_{t}$, this crowding-out effect is full, as all the debt is held by domestic creditors. Figure 10 helps us build intuitions on how the size and shape of the crowding-out region depends on the stock of debt and the quality of institutions. The top panel shows the effects of changes in $d_{t}$ for a fixed $p_{t+1}$, while the bottom panel shows the effects of changes in $p_{t+1}$ for a fixed $d_{t}$.

Without the credit constraint, the crowding-out region would not exist. To see this formally, recall that as $\phi$ grows, the credit constraint is relaxed. Indeed, in the the limit $\phi \rightarrow \rho$ the credit constraint becomes irrelevant. The reason is that each unit of credit, which requires payment of $\rho$ units of goods tomorrow, allows the investors to purchase one unit of capital, which produces pledgeable funds of $\rho$ units tomorrow. Thus, credit is unbounded. As we approach this limit, the law of motion in Equations (9)-(10) converges to:

$$
k_{t+1}=k^{*}
$$

Equation (11) simply says that, in the absence of a credit constraint, the patient young borrow enough to purchase the sovereign debt and invest until the return to investment equals the interest 
rate. Thus, sovereign debt does not affect investment and growth. ${ }^{21}$

\subsection{Secondary markets and discrimination}

When does the government default? When does the government discriminate between domestic and foreign creditors? There are three elements or assumptions that define our view of sovereign default. The first one is that the institutional framework within which governments operate impedes default in normal times. This is particularly true in European countries where judicial and parliamentary systems are strong and use their power to ensure that governments do not break the law and honor the contracts they sign.

The second element is that, even in European countries, the institutional framework fails sometimes and governments can act opportunistically and default. In the previous section, this meant always defaulting on foreign creditors and we explored two alternative scenarios with and without default on domestic creditors. These scenarios are simple and clear cut but, naturally, the picture is more nuanced once we think more deeply about the implications of acting opportunistically.

When it comes to domestic creditors, the choice to repay or default revolves around the identity of domestic debt holders and taxpayers. After all, defaulting on domestic debt is equivalent to making a transfer from the former to the latter. Whether the government favors such a transfer depends on political factors that are beyond the scope of this paper. But it seems reasonable to think that these factors fluctuate over time and, as a result, so does the preference of governments towards domestic default.

When it comes to foreign creditors, the choice to repay or default depends on the magnitude of international sanctions. Defaulting on foreign debt consists of a transfer from foreign debtholders to taxpayers. The traditional approach in the sovereign debt literature is that the government dislikes this transfer and the only deterrent to it is the fear of international sanctions. Whether the government defaults on foreign creditors depends on the size of the foreign debt relative to the cost of international sanctions. Once again, it seems reasonable to think that these sanctions fluctuate over time and, as a result, so does the preference of governments towards foreign default. ${ }^{22}$

The third element of our view is that the presence of secondary markets provides a link between the decisions to default on domestic and foreign creditors. ${ }^{23}$ As argued above, these decisions

\footnotetext{
${ }^{21}$ While the presence of a credit constraint is crucial for our results, its specific form is not. Appendix 2 shows the case in which sovereign debt can also be pledged as collateral.

${ }^{22}$ We shall choose one specific way to do this in Section 4 below.

${ }^{23}$ For a more thorough discussion see Broner et al. (2010).
} 
depend on different factors and there is no 'a priori' reason to expect equal treatment. And yet, secondary markets make it difficult for governments to discriminate between domestic and foreign creditors.

The argument is based on the classic notion that markets transfer assets to those that value them most. And this value is derived not only from differences in risk or patience, but also from differences in the ability to be repaid. For example, imagine that the government announces a policy to repay domestic creditors and default on foreigners. Then the latter has incentives to go to the secondary market and sell their debts to the former. Competition among domestic creditors ensures that these debts are purchased at face value. When the government pays the debt, it is already in the hands of domestic creditors. And even though foreigners are not paid 'de jure' they are paid 'de facto.' Thus, the government can only default on both groups or none.

Attempts at discrimination are more likely to succeed when secondary markets fail or work imperfectly. The presence of transaction costs and non-competitive behavior can reduce trade in secondary markets. Also, governments can impose capital controls to make it easier to discriminate. For these and other reasons, secondary markets sometimes fail to discipline governments and discrimination succeeds.

How should one model this rich and complex view of sovereign debt crises? We refer the reader to the papers cited in the introduction for a wide range of possible environments in which some these issues arise. Here the focus is less on the microfoundations of alternative default scenarios and more on their macroeconomic implications. Thus, we adopt the expedient device of defining the following set of repayment probabilities:

\begin{tabular}{|l|l|l|}
\hline Foreign $\backslash$ Domestic & Pay & Default \\
\hline Pay & $p_{t+1}$ & $p_{t+1}^{F}$ \\
\hline Default & $p_{t+1}^{D}$ & $1-p_{t+1}-p_{t+1}^{F}-p_{t+1}^{D}$ \\
\hline
\end{tabular}

There are four default scenarios. With probability $p_{t+1}$ both domestic and foreign creditors are repaid. This is the sum of the probability that institutions impose full repayment on the government and the probability that institutions fail but the government still repays in full. Also, $p_{t+1}^{F}$ and $p_{t+1}^{D}$ are the probabilities that institutions fail and the government repays, respectively, only foreign and only domestic creditors. Finally, $1-p_{t+1}-p_{t+1}^{F}-p_{t+1}^{D}$ is the probability that institutions fail and the government defaults on both domestic and foreign creditors. 
A key assumption that we use throughout is that discrimination is more likely against foreign creditors than domestic ones:

$$
p_{t+1}^{D} \geq p_{t+1}^{F}
$$

This assumption is crucial in what follows since the crowding-out effects that we emphasize here are the result of a wedge between the expected return to holding debt by domestic and foreign creditors, and this wedge is in turn a consequence of discriminatory treatment against foreigners in the event of default. When this assumption fails, the domestic private sector prefers to lend abroad than to the government, and the crowding-out effects that we emphasize here vanish.

To generalize the model in the previous section to account for this richer set of probabilities, we need first to replace Equation (8) by the following one:

$$
R_{t+1}=\min \left\{\frac{\rho}{p_{t+1}+p_{t+1}^{F}}, \frac{\alpha \cdot k_{t+1}^{\alpha-1}+1-\delta-\phi}{p_{t+1}+p_{t+1}^{D}} \cdot \frac{\rho}{\rho-\phi}\right\}
$$

Equation (13) recognizes that defaults do not always discriminate in favor of domestic creditors, and that it is even possible that they sometimes discriminate in favor of foreign creditors. We also need to replace $p_{t+1}$ in Equations (9)-(10) with the following variable:

$$
\tilde{p}_{t+1}=\frac{p_{t+1}+p_{t+1}^{F}}{p_{t+1}+p_{t+1}^{D}}
$$

where $\tilde{p}_{t+1}$ is the ratio of repayment probabilities to foreign and domestic creditors. Assumption (12) ensures that $\tilde{p}_{t+1} \leq 1$. These couple of simple adjustments generalize the model.

There are two additional aspects of discrimination that are worth mentioning. The first one is that discrimination might vary across different types of government debt. This might happen, for example, across currency denomination, jurisdiction of issuance, maturity, or issuing government agency. If the wedge between the domestic and foreign valuations varies across types of debt, the domestic private sector first purchases the type of debt with the highest wedge, then the one with the second-highest wedge, and so on. Ultimately, the size and shape of the crowding-out region depends on the valuation wedges and total stocks of the different classes of debt. ${ }^{24}$

The second aspect is that discrimination need not happen only in the event of default. The government could offer a favorable tax treatment to domestic debtholders, or it could impose

\footnotetext{
${ }^{24}$ Appendix 3 extends our model to the case of different maturities. It also identifies sufficient conditions for the valuation wedge to be the same for all maturities: (i) when the government defaults, it does so simultaneously on all maturities, and; (ii) in the event of a default, bonds of all maturities are treated equally.
} 
regulations on the portfolios of domestic residents that are fulfilled or relaxed by holding its debt. Whatever these additional advantages of holding domestic debt might be, they only reinforce our basic argument: that discrimination introduces a wedge between domestic and foreign valuations of debt, giving rise to crowding-out effects.

\section{Crowding-out effects: dynamics and efficiency}

In this section, we derive some implications of crowding-out effects. First, we show why some economies might eventually outgrow the crowding-out region and reach an equilibrium with high output, while others may be permanently trapped in equilibria with low investment and output. Second, we analyze the efficiency properties of these equilibria and discuss the distributive effects of efficiency-enhancing policies.

\subsection{Dynamics}

An interesting implication of the crowding-out region is that it gives rise to non-standard dynamics and the possibility of multiple steady states. We show this with the help of a sequence of examples in which (i) the government keeps the debt constant, i.e. $x_{t}=\left(R_{t}-1\right) \cdot d_{t}$; and (ii) the degree of discrimination also remains constant, i.e. $\tilde{p}_{t+1}=\tilde{p}$. These assumptions are helpful because they make the law of motion time-invariant and the system can be analyzed with standard graphical tools. $^{25}$

Moving over the panels of Figure 11, we find a sequence of economies with progressively higher degree of discrimination, i.e. lower $\tilde{p}$. Since increases in the probability of default raise the degree of discrimination, we use this sequence of examples to illustrate how changes in the probability of default affect the dynamics of the economy.

Panel (a) shows an economy where the probability of default is zero. In this economy, there is no crowding-out region. There is a single and stable steady state, $k_{H}^{*}$. As usual, the economy converges to this steady state monotonically.

Panel (b) shows an economy where the probability of default is small. This generates a small crowding-out region. The steady state does not change. But the crowding-out region slows down the rate of convergence towards it making the growth rate non-monotonic. Growth slows down

\footnotetext{
${ }^{25}$ These dynamics are all conditional on default not taking place, of course. Technically, once default occurs the debt goes to zero and the economy behaves as the baseline model of section 2.1. This only shows that our model has been designed to study the macroeconomic effects of a positive probability of default. It has not been designed to study the aftermath of default.
} 
when the country enters the crowding-out region and some of the savings that would have been invested are instead used to purchase sovereign debt. Only after all sovereign debt has been purchased by domestic creditors, additional savings are used for investment and growth picks up again. Eventually, the country exits the crowding-out region and reaches the steady state $k_{H}^{*}$.

Panel (c) shows an economy where the probability of default is intermediate, and so is the crowding-out region. An interesting novelty is that there are now two stable steady states $k_{H}^{*}$ and $k_{L}^{*}$, and an unstable one $k_{M}^{*}$. If the economy starts above $k_{M}^{*}$, the economy converges towards the high steady state $k_{H}^{*}$ outside the crowding-out region. Just as in the previous example, the convergence is slower and the growth rate non-monotonic. But these effects are only temporary, as the economy eventually exits the crowding-out region and reaches the high steady state $k_{H}^{*}$. If the economy starts below $k_{M}^{*}$, however, it converges to the low steady state $k_{L}^{*}$ inside the crowding-out region. As a result, crowding-out effects become permanent.

Panel (d) shows an economy with a high probability of default. The crowding-out region is so large that the high steady state no longer exists. The economy has a single steady state $k_{L}^{*}$ located inside the crowding-out region. Regardless of where the economy starts, crowding-out effects are always permanent as the economy converges towards the low steady state $k_{L}^{*}$.

This sequence of examples is suggestive of what might be happening in GIIPS. An increase in the probability of default has raised sovereign spreads and provided incentives for domestic creditors to purchase sovereign debt. This has created crowding-out regions. If these regions have not become too large, it might still be possible to outgrow them just by stabilizing debts, even without institutional reforms that lower the probability of default and sovereign spreads. It might take time for this to happen, of course, but GIIPS would eventually return to a high-output equilibrium. If these crowding-out regions have become too large, though, it might not be possible anymore to outgrow them without reducing debts and undertaking institutional reforms that lower the probability of default and sovereign spreads. Without these policy adjustments, GIIPS would remain permanently trapped in a low-output equilibrium.

\subsection{Efficiency}

Within the crowding-out region, the economy is inefficient in the traditional sense that a government that can transfer resources costlessly among domestic residents could implement a Pareto improvement. To see this, consider a given sequence of public debt $\left\{d_{s}\right\}_{s=t}^{\infty}$. In any period $t$, the repayment of this debt is financed partly through taxation and partly through the issue of new debt, 
$d_{t+1}$. This new debt, in turn, can be either sold to domestic creditors, in which case we denote it by $d_{t+1}^{D}$, or to foreign ones, in which case we denote it by $d_{t+1}^{F}$. Let $y_{t}$ be the total domestic income. Then, we have that:

$$
E_{t} y_{t+1}=k_{t+1}^{\alpha}+(1-\delta-\phi) \cdot k_{t+1}-\rho \cdot d_{t+1}^{F},
$$

where

$$
k_{t+1}=\frac{\rho}{\rho-\phi} \cdot\left(s \cdot k_{t}^{\alpha}-d_{t+1}^{D}\right) \text { and } d_{t+1}^{F}+d_{t+1}^{D}=d_{t+1} .
$$

Equation (15) shows the expected total income at time $t+1$. This includes output and undepreciated capital, net of expected credit payments by the domestic private sector and of debt payments to foreign creditors by the government. Since we are considering what happens in the crowding-out region, the expression implicitly assumes that the private sector is credit constrained by setting its credit payments equal to $\phi \cdot k_{t+1}$. It also takes into account that, in expectation, the unit cost of borrowing from foreign creditors equals $\rho$.

Consider next the effects of replacing one unit of foreign borrowing with one unit of domestic one, while keeping the total stock of debt constant. The derivative of total expected income with respect to $d_{t+1}^{D}$ equals

$$
\frac{\partial E_{t} y_{t+1}}{\partial d_{t+1}^{D}}=-\frac{\rho}{\rho-\phi} \cdot\left(\alpha \cdot k_{t+1}^{\alpha-1}+1-\delta-\phi\right)+\rho,
$$

which is negative whenever the private sector is credit constrained. Thus, increases in domestic debt reduce the economy's expected income. The reason is very intuitive: each unit of debt sold to foreign creditors has an expected cost equal to the interest rate, while each unit of debt sold to domestic creditors reduces investment and therefore has a cost equal to the return to investment. Since the return to investment exceeds the interest rate, an increase in domestic borrowing reduces total income by replacing a cheap (external) source of funds with an expensive (internal) one. Hence, the crowding-out effect imposes an inefficiency on the economy by reducing its total income.

Imagine that the government can adopt a policy that prevents domestic debt purchases altogether and gets rid of this inefficiency. It could do so, for instance, by eliminating the source of discrimination between domestic and foreign creditors. The gains from this policy are unevenly distributed, though. The patient young at time $t$ lose because this policy does not affect their wage but lowers the return to their savings. The young at $t+1$ gain from this policy, however, as they are born into an economy with more capital and higher wages. Because the economy's total income 
increases, the gains of the young at $t+1$ exceed the losses young at $t$. If the government could redistribute income from the latter to the former the policy could be made Pareto improving.

Outside the crowding-out region, there is no inefficiency associated with sovereign debt. If the capital stock is below the crowding-out region, the domestic private sector does not purchase any debt. If the capital stock is above the crowding-out region, the return to investment already equals the interest rate and there is no gain from reducing domestic debt holdings.

The model therefore suggests that repurchases of sovereign debt by the private sectors of GIIPS are inefficient, and policies that penalize these purchases would bring efficiency gains. The model also points at some of the political-economy problems that are likely to arise when policies of this sort are considered. The efficiency gains are likely to benefit future generations, while current generations experience loses. And the transfers that would ensure that everybody is made better off may or may not be politically feasible.

\section{Self-fulfilling crises and random crowding-out effects}

The model illustrates how increases in the probability of default worsen macroeconomic performance. But it misses a key element that seems to have been at play in recent years: a worsening macroeconomic performance also increases the probability of default. To sharpen our view of the European debt crisis, we endogenize default probabilities and provide a fuller picture of the interplay between macroeconomic performance and the probability of default. The key additional assumption is that default penalties increase with the economy's capital stock or output. We find that self-fulfilling crises are possible in a subset of the crowding-out region, which we label the "crisis zone". Within this zone, crowding-out effects are essentially random and depend on expectations.

\subsection{The model with endogenous defaults}

Assume next that: (i) institutions succeed at time $t+1$ and force the government to repay in full with probability $\pi_{t+1}$; (ii) if institutions fail, domestic creditors are always repaid. It follows then that $\tilde{p}_{t+1}=p_{t+1} \in\left[\pi_{t+1}, 1\right]$. What determines the probability of (discriminatory) default $1-p_{t+1}$ ? The conventional answer is that governments repay in order to avoid costly international sanctions, such as the loss of reputation, trade embargoes or even military interventions. When these penalties are large relative to the payments owed to them, governments repay; otherwise, they default. ${ }^{26}$

\footnotetext{
${ }^{26}$ When governments cannot discriminate between domestic and foreign creditors they might repay foreigners to avoid the cost of domestic default. This effect is absent here because we are ignoring costs of domestic defaults.
} 
We introduce these considerations into the model by assuming that, for each unit of debt that is defaulted upon, the country suffers a loss equal to a fraction $\lambda$ of the economy's capital stock. This loss could be interpreted as the result of sanctions or penalties imposed by defaulted creditors, or as the resources that taxpayers have to provide in order for the government to defend itself against the legal actions of creditors. Whatever the interpretation, we assume that it is a deadweight loss that does not report any benefits to the creditors themselves.

Foreign creditors are defaulted on if the benefits of doing so exceed the costs. The benefit of a default is the reduction in expected net payments from domestic taxpayers to foreigners. If we let $d_{t}^{F}$ denote the stock of debt in the hands of foreigners at time $t$, that benefit is equal to $R_{t} \cdot d_{t}^{F}$. The costs of a default are equal to $\lambda \cdot k_{t} \cdot R_{t} \cdot d_{t}^{F}$. Thus, a default on foreign creditors at time $t$ is optimal only if

$$
k_{t} \leq \lambda^{-1}
$$

Equation (16) provides the default decision rule. Its key aspect is that default depends negatively on the capital stock and, thus, on past investment. This feature is crucial for the results to come.

To assess whether full repayment may be sustained in equilibrium, imagine that foreign creditors at time $t$ are 'optimistic' and expect to be repaid in period $t+1$, i.e. $p_{t+1}=1$. Hence, there is no crowding-out effect and capital accumulation is given by the law of motion in Equation (5), or Equation (9) for $p_{t+1}=1$ :

$$
k_{t+1}=k_{+1}\left(k_{t} ; 1\right)
$$

To check whether these expectations are consistent with equilibrium, we just need to verify that the government repays foreign creditors at $t+1$ even when institutions fail. According to Equation (16), this is the case as long as $k_{+1}\left(k_{t}, 1\right) \geq \lambda^{-1}$. Thus, if we define

$$
k^{O}= \begin{cases}\min \left\{k: k_{+1}(k, 1)=\lambda^{-1}\right\} & \text { if } \lambda^{-1} \leq k^{*} \\ \infty & \text { if } \lambda^{-1}>k^{*}\end{cases}
$$

there exists an optimistic equilibrium at time $t$ as long as $k_{t} \geq k^{O}$.

The intuition behind Equation (18) is clear. In the optimistic equilibrium the government repays foreigners because $k_{t+1}$ and, thus, the cost of default are so high that defaulting on foreigners is not worth its cost. In such an equilibrium, everyone expects the government to repay its foreign creditors: because of this, there is no crowding out effect and domestic investment is high, which raises the costs of default ex-post and validates expectations. Since $k_{+1}(\cdot ; 1)$ is weakly increasing, if 
the optimistic equilibrium exists for a given $k_{t}$ it will also exist for higher levels of the capital stock. This is why there is a threshold level $k^{O}$ such that the optimistic equilibrium exists if $k_{t} \geq k^{O}$. If $\lambda^{-1}>k^{*}$, however, this equilibrium cannot exist: even if foreign creditors expect to be fully repaid, the cost of default is so low that government finds it optimal to default even if the unconstrained level of capital is achieved. The solid line of Figure 12 below illustrates the optimistic law of motion for the case in which $\lambda^{-1}<k^{*}$.

The economy can also display a 'pessimistic' equilibrium. In this equilibrium the government repays foreigners at $t+1$ only when institutions succeed, i.e. $p_{t+1}=\pi_{t+1}$. If foreigners expect to be repaid with probability $\pi_{t+1}$, they are less willing to buy government debt, there is more scope for crowding out, and capital accumulation is given by the law of motion of Equation (9) for $p_{t+1}=\pi_{t+1}:$

$$
k_{t+1}=k_{+1}\left(k_{t}, \pi_{t+1}\right) .
$$

To check whether this is an equilibrium, we need to verify that the government actually prefers to default on foreign creditors at $t+1$ when institutions fail. According to Equation (16), this is the case as long as $k_{+1}\left(k_{t}, \pi_{t+1}\right) \leq \lambda^{-1}$. Thus, if we define,

$$
k^{P}= \begin{cases}\max \left\{k: k_{+1}\left(k, \pi_{t+1}\right)=\lambda^{-1}\right\} & \text { if } \lambda^{-1} \leq k^{*} \\ \infty & \text { if } \lambda^{-1}>k^{*}\end{cases}
$$

there exists a pessimistic equilibrium at time $t$ whenever $k_{t} \leq k^{P}$.

The intuition behind Equation (20) is also clear. In the pessimistic equilibrium the government defaults on foreigners because $k_{t+1}$ and, thus, the cost of default are so low that repaying foreigners is not worth its cost. In such an equilibrium, everyone expects the government to default when institutions fail: because of this, the risk premium on debt is high, which leads to crowding out of domestic investment, and in turn lowers the costs of default and validates expectations. Since $k_{+1}\left(\cdot, \pi_{t+1}\right)$ is weakly increasing, if the pessimistic equilibrium exists for a given $k_{t}$ it will also exist for lower levels of the capital stock. That is why there is a threshold level $k^{P}$ such that the pessimistic equilibrium exists if $k_{t} \leq k^{P}$. The pessimistic law of motion is depicted by the dashed line in Figure 12. Because $k_{+1}\left(k, \pi_{t+1}\right) \leq k_{+1}(k, 1)$ for all $k$, it follows from Equations (18) and (20) that $k^{P} \geq k^{O}$.

The law of motion has at least two distinct parts or sections. For low capital stocks, $k_{t} \leq$ $k^{O}$, only the pessimistic equilibrium exists. For high capital stocks $k_{t} \geq k^{P}$, only the optimistic 
equilibrium exists. If $k^{P}=k^{O}$, the law of motion contains no other part or section. If $k^{P}>k^{O}$, the law of motion contains a third additional part or section in which $k^{O}<k_{t}<k^{P}$. We refer to this section as the "crisis zone". Within it, both the pessimistic and optimistic equilibria exist and outcomes depend on expectations. As usual, we model these expectations with a sunspot variable that takes two values, 'optimism' and 'pessimism'.

The crisis zone is a subset of the crowding-out region for the simple reason that, outside this region, $k^{O}=k^{P}$ and both equilibria cannot exist simultaneously. But the existence of a crowdingout region does not guarantee the existence of a crisis zone. If $\lambda$ is either too small or too large, only the pessimistic or only the optimistic equilibria exist within the crowding-out region. For both equilibria to coexist, $\lambda$ must take intermediate values. ${ }^{27}$

\subsection{Dynamics with crisis zones}

When the economy visits the crisis zone it might experience substantial volatility. This volatility is not caused by any fundamental shocks, but instead by fluctuations in investor sentiment. In optimistic periods, foreign creditors purchase the sovereign debt at zero spreads. The domestic private sector uses all its resources to invest. As a result, growth is high and the probability of default drops to zero. In pessimistic periods, foreign creditors are reluctant to purchase the debt and require large spreads. Thus, some (or all) of this debt is purchased by domestic creditors and this crowds out investment. As a result, growth is low and the probability of default is high. Alternating optimistic and pessimistic periods generate volatility in spreads and the share of sovereign debt that is in the hand of domestic and foreign creditors. It also generates volatility in investment and growth.

An interesting question is whether visits to the crisis zone are permanent or temporary. And, if temporary, what determines whether the economy will exit from above and converge to a highoutput equilibrium or, instead, exit from below and converge to a low-output equilibrium. We illustrate different possibilities in Figure 13 using four examples in which (i) the government keeps the debt constant, i.e. $x_{t}=\left(R_{t}-1\right) \cdot d_{t}$; and (ii) the quality of institutions remains constant, i.e. $\pi_{t}=\pi$. Under these assumptions the laws of motion are time invariant and the system can be

\footnotetext{
${ }^{27}$ Unlike other models in the sovereign-debt literature (and reviewed in the introduction), the maturity structure of debt is basically irrelevant here. To understand why this is the case, consider a government that has issued debts of different maturities. If expectations are pessimistic, foreign creditors can sell both maturing and non-maturing debts to domestic creditors. Thus, the potential for crowding-out depends on the full amount of debt, not only on maturing debts. We show this in Appendix 3 where we extend the model to the case of different maturities.
} 
analyzed with simple graphical tools. ${ }^{28}$

In all the examples of Figure 13, we depict economies that have two stable steady states, $k_{L}^{*}$ and $k_{H}^{*}$. In the high steady state, the probability of default is zero. In the low steady state, the probability of default is $1-\pi$. In all examples, we have chosen a value of $\lambda$ that ensures that there is a crisis zone within the crowding-out region.

Panel (a) shows an example in which both steady states are within the crisis zone. Regardless of the initial condition, the economy always converges to the crisis zone. Once inside this zone, the economy never leaves it. The two steady states act as barriers that impede the economy to go below $k_{L}^{*}$ or above $k_{H}^{*}$. Thus, the economy wanders between these two values forever. In optimistic periods, the probability of default is low and investment and growth are high. In pessimistic periods, the probability of default is high and investment and growth are low.

Panels (b) and (c) show examples in which one steady state lies within the crisis zone and the other one outside. The only absorbing steady state is the one outside of the crisis zone. Even if the economy is arbitrarily close to the steady state inside the crisis zone, a sequence of investor sentiment shocks can take the economy close enough to the other steady state and outside of the crisis zone. Thus, the economy in panel (b) eventually will reach the high steady state with zero probability of default, while the economy in panel (c) will reach the low steady state with a high probability of default. Convergence towards the absorbing steady state might take time and, while in the crisis zone, the economy might be subject to an arbitrarily large number of cycles of optimism and pessimism.

Panel (d) shows an example in which both steady states lie outside the crisis zone. Thus, both of them are absorbing states. If the economy starts above the crisis zone, it converges to the high equilibrium. If the economy starts below the crisis zone, it converges to the low equilibrium. If the economy starts within the crisis zone, it will eventually exit it. But only luck determines how this happens. A long enough sequence of optimism would lead to an exit above and convergence to the high steady state. A long enough sequence of pessimism would lead to an exit below and convergence towards the low steady state.

These examples suggest another interpretation of what might be happening in GIIPS. Perhaps the deep recessions and the uncertainties that followed the financial crisis of 2007 had already placed these countries inside the crisis zone. Optimistic market expectations kept sovereign spreads low for a while. But events in late 2009, and most notably Greece's revelation that its deficits were larger

\footnotetext{
${ }^{28}$ Once again, we remind the reader that these dynamics are all conditional on default not taking place.
} 
than reported, caused market expectations to turn pessimistic. Looking forward, one might ask what it takes to ensure that GIIPS exit the crisis zone from above. If the high steady state is inside the zone, this might require a substantial reduction in their debts that shrinks the crowding-out region until the high steady state falls outside of the crisis zone. In the meantime, there is a role for policies that coordinate market expectations towards the optimistic equilibrium.

\section{$5 \quad$ Spillovers and transfers}

We have so far considered a small open economy interacting with a passive international financial market. In Europe, though, foreign governments and European institutions are playing an increasingly important role in sovereign debt markets. To understand this behavior and its possible effects, this section extends our analysis to the case of an economic union. The key assumption is that creditor discrimination is relatively low within the union. We show how debtor countries export crowding-out effects to the rest of the union. We study how these spillover effects shape the dynamics of the whole union, and then analyze the role of transfers among union members.

\subsection{The model with an economic union}

Assume next that the economy belongs to an economic union. For our purposes, the defining feature of the economic union is that residents of the union receive preferential treatment in the event of default. Members of an economic union are also likely to have more integrated goods and factor markets. We abstract from these issues here, though, to keep the analysis manageable. ${ }^{29}$

The government, like all other governments in the union, pays its debt to domestic creditors, to creditors in the rest of the union, and to creditors outside the union with probabilities $1, p_{U, t+1}$, and $p_{t+1}$, respectively. Naturally, $1 \geq p_{U, t+1} \geq p_{t+1} \geq 0$. When $p_{U, t+1}=1$, creditors in the rest of the union are treated as domestic creditors. When $p_{U, t+1}=p_{t+1}$, creditors in the rest of the union are treated as creditors outside the union. Although there are other ways to interpret this parametrization, in what follows we emphasize the probability of exiting the union. In particular, we think of $1-p_{U, t+1}$ as the probability that there is a default and the country exits the union, in which case creditors in the rest of the union are treated as foreign. Similarly, we think of $p_{U, t+1}-p_{t+1}$ as the probability that there is a default and the country stays in the union, in which

\footnotetext{
${ }^{29}$ Another manageable approach would be to re-interpret the model developed so far as a model for the union and define member countries as subsets of the population. This alternative approach assumes that goods and factors markets are so integrated that wages and rental rates are equalized across the union.
} 
case creditors inside the union are treated as domestic. Thus, when we refer to an increase in the probability of exiting the union we are specifically referring to a decline in $p_{U, t+1}$, holding $p_{t+1}$ constant. ${ }^{30}$

To determine the interest rate on the debt, we now must take into account that there are three potential marginal buyers: domestic creditors, creditors in the rest of the union, and creditors outside the union. Their expected returns to holding the sovereign debt are $R_{t+1}, R_{t+1} \cdot p_{U, t+1}$ and $R_{t+1} \cdot p_{t+1}$, respectively. Define $\rho_{U, t+1}$ as the lowest return to investment in the rest of the union. For further reference, we note that $\rho_{U, t+1} \geq \rho$ since residents of the union never invest beyond the point in which the return to investment equals the interest rate. With this notation, we can write the contractual interest rate as follows:

$$
R_{t+1}=\min \left\{\frac{\rho}{p_{t+1}}, \frac{\rho_{U, t+1}}{p_{U, t+1}},\left(\alpha \cdot k_{t+1}^{\alpha-1}+1-\delta-\phi\right) \cdot \frac{\rho}{\rho-\phi}\right\}
$$

Equation (21) shows how the interest rate varies with the marginal buyer and should be familiar at this point. The only novelty is that there is now a new set of creditors from the rest of the union. These creditors are willing to purchase the debt if $R_{t+1} \cdot p_{U, t+1}$ is as large as $\rho_{U, t+1}$.

Assume now that our economy is small relative to the union so that we can take $\rho_{U, t+1}$ as exogenous. We can then write the law of motion of the capital stock as follows:

$$
k_{t+1}=\left\{\begin{array}{l}
\min \left\{\frac{\rho}{\rho-\phi} \cdot s \cdot k_{t}^{\alpha},\left(\frac{\alpha}{(\rho-\phi) \cdot \min \left\{1 / p_{t+1}, \rho_{U, t+1} /\left(\rho \cdot p_{U, t+1}\right)\right\}+\phi+\delta-1}\right)^{\frac{1}{1-\alpha}}\right\} \begin{array}{c}
\text { if } k_{t}<\bar{k}_{t} \\
\min \left\{\frac{\rho}{\rho-\phi} \cdot\left(s \cdot k_{t}^{\alpha}-d_{t}\right),\left(\frac{\alpha}{(\rho-\phi) \cdot \min \left\{\rho_{U, t+1} / \rho, p_{U, t+1} / p_{t+1}\right\}+\phi+\delta-1}\right)^{\frac{1}{1-\alpha}}\right\} \\
\text { if } k_{t} \geq \bar{k}_{t}
\end{array}
\end{array}\right.
$$

where $\bar{k}_{t}$ is defined as

$$
\frac{\rho}{\rho-\phi} \cdot\left(s \cdot \bar{k}_{t}^{\alpha}-d_{t}\right)=\left(\frac{\alpha}{(\rho-\phi) \cdot \min \left\{1 / p_{t+1}, \rho_{U, t+1} /\left(\rho \cdot p_{U, t+1}\right)\right\}+\phi+\delta-1}\right)^{\frac{1}{1-\alpha}}
$$

Equations (22)-(23) show the law of motion of the capital stock in the presence of an economic union. A comparison of Equations (22)-(23) and (9)-(10) reveals that the economic union affects the law of motion through $\rho_{U, t+1}$. This return depends on the whole distribution of capital stocks and sovereign debts in the union.

\footnotetext{
${ }^{30}$ To simplify the discussion, we ignore the possibility of multiple equilibria. That is, we assume that default penalties are negligible.
} 
Figure 14 plots the law of motion with and without the economic union for this case. The solid line shows the familiar case without a union which we have studied so far, while the dashed line shows the new case with a union. The figure shows that belonging to an economic union affects the law of motion of our economy in two regions.

First, there is a range of relatively low capital stocks where the union shifts the law of motion up. This happens because the contractual rate on the debt is lower due to the lower probability of defaulting on other union members: $p_{U, t+1}>p_{t+1}$. The return to investment is high in this range of capital stocks. Without the union, though, the domestic private sector would reduce investment to purchase all or part of the debt since the contractual interest rate is even higher. But the preferential treatment granted to creditors in the rest of the union lowers the contractual interest rate and reduces domestic purchases. In this range of capital stocks, our economy is effectively exporting crowding-out effects to the rest of the union. This raises investment and growth.

Second, there is a range of relatively high capital stocks where the union shifts the law of motion down. This happens because all members of the union are credit constrained and the lowest return to investment in the union exceeds the interest rate: $\rho_{U, t+1}>\rho$. The return to investment is low in this range of capital stocks. Without the union, though, domestic creditors would use additional funds to invest since the interest rate is even lower. But the preferential treatment that domestic creditors receive from other members of the union induces the private sector to stop investing and instead purchase debt from other union members. In this range of capital stocks, our economy is effectively importing crowding-out effects from the rest of the union. This lowers investment and growth.

The union therefore redistributes crowding-out effects from members that have low capital stocks and high debts, towards members that have high capital stocks and low debts. The importance of this re-distribution depends on how preferential the treatment of creditors within the union is. As this preferential treatment increases the crowding-out effect moves away from union members that issue the debt and towards the richer union members.

\subsection{Dynamics of an economic union}

The analysis so far has considered the cross-sectional implications of an economic union. To have a complete analysis of the dynamics of the union, we cannot take $\rho_{U, t+1}$ as given. As mentioned above, $\rho_{U, t+1}$ is the lowest return to investment in the union. Thus, this return must be determined endogenously together with the whole distribution of capital stocks in the union. 
To show some of the implications of the theory, we consider a simple example in which the union has two sets or groups of countries with equal populations. North countries have high initial capital stocks. South countries have low initial capital stocks. Within each group there is no heterogeneity. As a result, each group can be treated as if it were a single country, and the whole union can be treated as a two-country union. We want to determine how debt affects convergence and growth within the union.

Figure 15 shows four simulations of the model. In all of them, the union starts in period $t=0$ without debt. For a while, both South and North grow towards their common steady states. Since South starts out with a lower capital stock, it grows faster than North. In period $t=6$, South issues an amount of debt $d$ to finance consumption and then keeps this debt constant from then onwards. We choose parameter values such that both South and North are credit constrained even in the long run. The four panels in Figure 15 show the effects of debt on growth and convergence for different levels of debt $d$ and the probability of a union breakup $1-p_{U, t+1}$.

Panel (a) shows the dynamics of South and North when debt $d$ is small and the probability of breakup $1-p_{U, t+1}$ is low. In this case, debt generates a mild recession. The recession affects North to a greater extent since South exports most of the crowding-out effects. As a result, growth slows down in the union but convergence accelerates. In the long run, South and North converge to a similar steady state with South's debt evenly divided between South and North.

Panel (b) illustrates the case of small debt and high probability of a breakup. Since debt is small, the recession is mild as in the previous case. But the high probability of breakup implies that the crowding-out effects are stronger in the country that issued the debt. Thus, the recession affects South more than North and convergence slows down. In the long run, South converges to a steady state that is lower than North's as most of the debt remains in South.

Panel (c) shows the case in which debt is large and the probability of breakup is low. The large debt generates a much larger recession than in the previous two cases. But the low probability of breakup means that the recession is more severe in North and convergence speeds up. The large debt also leads to a much lower steady state in both South and North. But since the probability of breakup is low the debt is held in both South and North and their steady states are similar.

Finally, panel (d) shows the case of large debt and high probability of breakup. The recession is severe and, due to the high probability of breakup, its effects are concentrated in South. Convergence falls both in the short and in the long run, as the crowding-out effects remain concentrated in South. This is the case that resembles the most what we have observed in Europe since the 
start of the crisis. However, it does not capture the potential role of official creditors, who can lean against these forces driving private investment decisions and affect growth outcomes. We turn to this next.

\subsection{A role for transfers}

If there are crowding-out effects within the union, the equilibrium is inefficient in the same sense that we discussed in section 3, i.e., if governments could transfer resources costlessly among residents of the union they could implement a Pareto improvement. Imagine, for instance, that governments adopt a policy that prevents debt purchases within the union, and get rid of this inefficiency. This policy necessarily raises the income of the union as a whole because it allows governments to borrow from foreigners at a unit cost of $\rho$ and frees up union resources for productive investment, which has a higher return than $\rho$. The gains from this policy are unevenly distributed within the union, though. Countries that issue debt gain, because now they can do so at a lower interest rate. Countries that purchase debt lose despite being the ones that suffer the crowding-out effect of this debt. The reason is that now they receive a lower interest rate on their savings. Because the union's total income increases, though, it is always possible to redistribute income so as to attain a Pareto improvement. The interesting twist is that this requires redistribution across countries, which might be hard to coordinate among national governments.

Even if the union's private sectors cannot be prevented from purchasing debt, they might be 'discouraged' from doing so through government intervention. This can be done insofar as the quality of institutions varies across union members. To see this, consider again the case of a union with two groups of countries, South and North. In South, the government: (i) keeps the debt constant and equal to $d_{S}$, and; (ii) repays domestic creditors, North creditors and creditors outside the union with probabilities $1, p_{U}$ and $p_{S}$, respectively, where $p_{U} \geq p_{S}$. In North, there is no debt to begin with and the government repays all creditors with probability 1 . In this case, the debt of South pays a risk premium and it tends to crowd out capital accumulation within the union, possibly in North.

Imagine that the government of North intervenes to outbid the union's private sector and purchase the debt of South itself. It can finance this purchase by selling an amount $d_{N}$ of debt to outside creditors. ${ }^{31}$ Because North always repays all creditors, Equation (21) says that the interest

\footnotetext{
${ }^{31}$ This is actually the way both the EFSF and the ESM work. These institutions use the capital provided by the various euro-area countries to safely borrow at low rates and grant loans to stressed countries at a cost below their respective market rates.
} 
rate on its debt is $R_{N, t+1}=\rho$. The key aspect of such a debt purchase by North is that it lowers the interest rate at which South borrows, $R_{S, t+1}$ : by taking debt away from the union's private sector, it fosters capital accumulation within the union and reduces $\rho_{U, t+1}$. Once $d_{N}=d_{S}$ and all of South's debt is held by the government of North, the union's private sectors do not hold any debt and $R_{S, t+1}$ is determined by some bargaining process between both governments. ${ }^{32}$

What are the effects of such a policy? Whenever $d_{N}>0$, South is partly borrowing from outside creditors by using North as an intermediary. From the perspective of the union as a whole, this raises total expected income. The reason is, once again, the one we have outlined for the case of a single country: every time the government of North purchases a bond of South, it increases debt funding by creditors outside of the union (at an expected cost of $\rho$ ) at the expense of debt funding by the union's private sectors (at a cost higher than $\rho$ ). To maximize the total resources of the union, North would therefore have to set $d_{N}=d_{S}$ and completely eliminate the crowding-out effect.

The benefits of this policy might be unevenly distributed, though. South clearly benefits because it is able to borrow at a lower interest rate: from its perspective, $d_{N}$ should be as large as possible. The effects on North, however, are ambiguous. To see this, let $d_{S}^{N}$ denote the debt of South that is held by the private sector of North. In this case, the total income of North at time $t+1$ is given by

$$
E_{t} y_{N, t+1}=k_{N, t+1}^{\alpha}+(1-\delta-\phi) \cdot k_{N, t+1}+\left(d_{S, t+1}^{N}+d_{N}\right) \cdot p_{U} \cdot R_{S, t+1}-d_{N} \cdot \rho
$$

where

$$
k_{N, t+1}=\frac{\rho}{\rho-\phi} \cdot\left(s \cdot k_{N, t}^{\alpha}-d_{S, t+1}^{N}\right)
$$

Equation (15) denotes the total amount of goods available to residents of North at time $t+1$ : it includes output and undepreciated capital, as well as debt payments received by the domestic private sector and profits made by the government of North as a consequence of its intermediation. The expression implicitly assumes that the private sector is credit constrained by setting its credit payments equal to $\phi \cdot k_{N, t+1}$.

By substituting Equation (25) into Equation (15), we can compute the derivative of North's

\footnotetext{
${ }^{32}$ Even in this case, of course, it must be that $R_{S, t+1} \leq \frac{\rho_{U, t+1}}{p_{U}}$ because otherwise the union's private sector would demand debt.
} 
total income with respect to $d_{N}$ as

$$
\frac{\partial E_{t} y_{N, t+1}}{\partial d_{N}}=\left(p_{U} \cdot R_{S, t+1}-\rho\right)+\left(d_{S, t+1}^{N}+d_{N}\right) \cdot p_{U} \cdot \frac{\partial R_{S, t+1}}{\partial d_{N}} .
$$

Equation (26) says that an increase in $d_{N}$ has opposing effects on the total income of North. The first term captures the profits made by North on each unit of debt that it intermediates, and it could be positive of negative depending on $R_{S, t+1}$. The second term captures the effect of $d_{N}$ on $R_{S, t+1}$, which is always negative: as long as North is a creditor of South, the fall in $R_{S, t+1}$ reduces its income. The net effect of a transfer or debt-purchase scheme on the total income of North is thus unclear.

These results suggest that, if left to decide the size of such an intermediation scheme on its own, North might suboptimally set $d_{N}<d_{S}$ or it might even choose not to set up a scheme at all. If North could be properly compensated for intermediating the entire stock of South's debt, however, it would do so and fully eliminate the crowding-out effect. There is nothing in our union to prevent this compensation, though! South can always issue additional debt $d^{\prime}$ and 'give' it to the government of North in exchange for running the optimal scheme. Because we know that the total income of the union is maximized when $d_{N}=d_{S}$, this compensation can always be tailored to raise the income of both countries.

The main message of this section is that an economic union maximizes its income by channeling its external borrowing through its most 'credible' members. To illustrate this, we have focused on the extreme case in which North always repays creditors outside of the union. This means that $R_{N, t+1}=\rho$, so that an intermediation scheme like the one proposed can fully eliminate crowdingout effects within the union. The same logic would apply if North only repaid creditors from outside of the union with probability $p_{N}<1$, though. The only difference is that the debt issued by North as part of the scheme would then pay an interest rate $R_{N, t+1}=\frac{\rho}{p_{N}}$. Although, at this interest rate, North might still be able to intermediate for South, it might not be able to fully eliminate the crowding-out effects of debt.

\section{Back to Europe: What have we learned?}

The paper began with a description of the European sovereign debt crisis and a number of questions. We can now return to these questions and see how the model we presented helps address them. 
Why have sovereign spreads increased so much? Because the probability of sovereign default has increased, for which our model offers two explanations. The first is a decline in the quality of institutions, i.e., a decrease in $p$. According to this view, spreads increased in 2009 because there was a fundamental shift in the way that GIIPS' economies were perceived: news of data manipulation in Greece and weak economic performance made investors realize that, despite years of convergence, institutional quality in these economies still lagged behind the rest of Europe. The second explanation is that spreads rose because there was a shift in investor sentiment, i.e., because the economy shifted to a pessimistic equilibrium. According to this view, institutional quality had always been relatively low in GIIPS, but this did not lead to a high probability of default until international investors became pessimistic and reduced their demand for GIIPS' sovereign debt. Whether the originating shock was a decline in institutional quality or a decline in the demand of debt by international investors, the outcome was an increase in the probability of default.

\section{Why, in the midst of a deep recession, have the private sectors of GIIPS purchased} the debts of their sovereigns? Because when the risk of default increases, sovereign debt offers a higher expected return to domestic creditors than to foreigners; in other words, there is discrimination in favor of domestic creditors. Discrimination may take the form of domestic creditors being less likely to be defaulted on, or, equivalently, more likely to be compensated in the event of a default. It may also arise because of regulatory bias or moral suasion. As the sovereign spreads of GIIPS increased, so did the expectation of creditor discrimination and thus domestic demand for sovereign debt.

What are the economic consequences of these domestic purchases of debt? In the absence of financial frictions, none: after all, domestic creditors could always finance these purchases by borrowing from foreigners. If domestic creditors are constrained, though, these purchases crowd out private credit and investment. In the model, this pushes the economy into the crowding-out region, which reduces growth and may lead to self-fulfilling crises. ${ }^{33}$ In terms of GIIPS' economies, these purchases have prolonged the recession and exposed these countries to volatility driven by shifts in creditor expectations. Going forward, the model tells us that these crowding-out effects may be temporary or permanent depending on the stock of debt. Economies with low levels of debt

\footnotetext{
${ }^{33}$ The negative effect of public indebtedness on growth is consistent with the evidence reported by Reinhart and Rogoff (2010) and Reinhart, Reinhart, and Rogoff (2012). Our model makes the additional prediction that, everything else equal, public debt held domestically should have a more negative effect on growth than public debt held by foreigners. The reason is that while the taxes needed to repay the debt (which for simplicity we assumed to be non-distortionary) do not depend on who holds the debt, only domestic holdings crowd out domestic investment.
} 
eventually exit the crowding-out region and return to normal and stable growth rates. Economies with high levels of debt, though, may be permanently trapped within the crowding-out region.

What are the key inefficiencies that these purchases generate? If the domestic private sector is financially constrained, domestic purchases of debt are inefficient because they reduce the economy's total stock of resources. In the model, governments can always sell a unit of debt to foreign creditors by paying the international interest rate in expectation. This is what an economy saves if this unit of debt is instead purchased by a domestic creditor. At the same time, though, this purchase displaces productive investment. As long as investment is constrained and its productivity exceeds the international interest rate, the economy as a whole loses from these purchases because they replace a cheap, external source of debt financing with an expensive, internal one.

What is the right set of policies to address them? The goal of policy should be to get the economy out of the crowding-out region. An immediate way of doing this is to eliminate the source of creditor discrimination: this might be hard to do in practice, though, because it requires a credible commitment to treat all creditors equally. A more realistic alternative is to exert a fiscal effort to reduce the debt burden. This 'austerity' policy reduces consumption in the short run, as taxes are raised, but it eventually boosts growth by eliminating the crowding-out effect. It is interesting to note that there can be threshold effects associated with this policy. In order for the policy to raise investment and restore growth, debt must be reduced below the level of current domestic holdings. Otherwise austerity reduces current consumption but has no expansionary effects. Thus, the model suggests that there are nonlinear benefits to austerity programs like the ones adopted in GIIPS.

What difference does it make that GIIPS belong to the euro zone? It makes a big difference. The key assumption here is that creditor discrimination is relatively low within a union like the euro zone. Under this assumption, a country's debt is purchased by other union members and the crowding-out effect is shared with the rest of the union. The absence of discrimination within the union generates a larger market for debt issued by its members. This provides an alternative interpretation for the increase in spreads that began late in 2009: as the recession dragged on, a break-up of the euro zone began to be perceived as a possibility. ${ }^{34}$ This reduced the demand for GIIPS' debts, as residents of other euro-zone countries began to look increasingly

\footnotetext{
${ }^{34}$ In its European edition of December 2nd, 2010 The Economist dedicated a full-length article to this possibility.
} 
like foreign creditors. It also led to the shift in debt holdings towards domestic creditors. This concentrated crowding out in these economies and led to the observed divergence in growth rates within the euro zone.

Is there a role for Europe-wide policy? Yes, our model can rationalize two types of policies. First, regardless of the origin of the crisis, it shows how the 'safe' countries of a union can intermediate between the international financial market and the union's distressed members. This intermediation reduces crowding out and raises growth in the countries with weak institutions. In fact, the loans to GIIPS' by the European Financial Stabilization Facility (EFSF) and the European Stability Mechanism's facilities for purchasing debt both in primary and secondary markets can be thought of as such a policy. ${ }^{35}$ But, as we have shown, this intermediation can hurt safe countries if they are not properly compensated. This might be one reason why the EFSF has been quite unpopular among the euro zone's safe members, who perceive it as a covert transfer to the rest of the union. Second, if the crisis is self fulfilling, our model also shows that a European intervention could be beneficial and even entail no costs. In this case, the focus of the policy should be to coordinate creditors by eliminating the pessimistic equilibrium. One such measure is a commitment by other members of the euro zone to purchase the debt at face value regardless of the risk of default: if this commitment is credible, the crisis is avoided and no purchases are actually required. In fact, this is exactly the policy that has been carried out since August 2012 by the ECB. Under the Outright Monetary Transactions (OMT) program, the ECB has promised to purchase unlimited amounts of GIIPS' debts in secondary markets to maintain low spreads and facilitate the transmission of monetary policy. ${ }^{36}$

From a conceptual standpoint, this paper focuses on an important implication of the institutional changes that have taken place in sovereign debt markets over the past few decades. Nowadays, most governments borrow by selling bonds that are traded in deep secondary markets. One consequence of this trade is that it can improve repayment by transferring debts to individuals that are more likely to be repaid. Close to maturity, secondary markets reduce the probability of default and make it difficult for governments to discriminate among creditors. Before maturity, however, trading in secondary markets can interfere with the allocation of resources, displacing productive investment, reducing growth, and potentially giving rise to self-fulfilling crises. ${ }^{37}$ The interaction

\footnotetext{
${ }^{35}$ For a detailed description of these debt-purchase programs see www.esm.europa.eu/index.htm.

${ }^{36}$ Although less explicitly, bond purchases under the earlier ECB's SMP program and the current ESM play a similar role.

${ }^{37}$ In this paper, we have emphasized the crowding-out effects of domestic purchases of government debt before
} 
between trade in decentralized secondary markets, default risk, and economic outcomes is crucial for understanding modern sovereign debt crises, and it remains and exciting and fruitful research agenda.

\section{References}

[1] Aguiar, M., and M. Amador, (2011). "Growth in the shadow of expropriation," Quarterly Journal of Economics 126, 651-97

[2] Aguiar, M., M. Amador, E. Farhi, and G. Gopinath, (2013). "Crisis and commitment: Inflation credibility and the vulnerability to sovereign debt crises," Mimeo

[3] Aguiar, M., M. Amador, and G. Gopinath, (2009). "Investment cycles and sovereign debt overhang," Review of Economic Studies 76, 1-31

[4] Andritzky, J., (2012). "Government bonds and their investors: What are the facts and do they matter?" IMF Working Paper 12/158

[5] Ardagna, S., and F. Caselli, (2012). "The political economy of the Greek debt crisis: A tale of two bailouts," Centre for Economic Performance Special Paper 25

[6] Arslanalp, S., and T. Tsuda, (2012). "Tracking global demand for advanced economy sovereign debt," IMF Working Paper 12/284

[7] Bai, Y., and J. Zhang, (2012). "Duration of sovereign debt renegotiation," Journal of International Economics 86, 252-68

[8] Bolton, P., and O. Jeanne, (2011). "Sovereign default risk and bank fragility in financially integrated economies," IMF Economic Review 59, 162-94

[9] Broner, F., T. Didier, A. Erce, and S. Schmukler, (2013). "Gross capital flows: Dynamics and crises," Journal of Monetary Economics 60, 113-33

[10] Broner, F., A. Martin, and J. Ventura, (2010). "Sovereign risk and secondary markets," American Economic Review 100, 1523-55

maturity because they provide a natural explanation for many aspects of the European crisis. But in some cases these purchases can have countervailing effects. For example, if it is difficult to discriminate between domestic and foreign creditors a higher share of debt held domestically can reduce the incentives to default. This effect is emphasized in Brutti (2011) and Gennaioli et al. (forthcoming). 
[11] Broner, F., and J. Ventura, (2010). "Rethinking the effects of financial liberalization," Mimeo

[12] Broner, F., and J. Ventura, (2011). "Globalization and risk sharing," Review of Economic Studies 78, 49-82

[13] Brutti, F., (2011). "Sovereign defaults and liquidity crises," Journal of International Economics $84,65-72$

[14] Brutti, F., and P. Sauré (2013). "Sovereign debt crises and bond ownership: Testing the secondary market theory," Mimeo

[15] Calvo, G., (1988). "Servicing the public debt: The role of expectations," American Economic Review 78, 647-61

[16] Catão, L., A. Fostel, and R. Ranciere, (2012). "Fiscal discoveries, stops and defaults," Mimeo

[17] Cole, H., and T. Kehoe, (2000). "Self-fulfilling debt crises," Review of Economic Studies 67, 91-116

[18] Conesa, J., and T. Kehoe, (2013), "Gambling for redemption and self-fulfilling debt crises," Mimeo

[19] Corsetti, G., and L. Dedola, (2012). "The mystery of the printing press: Self-fulfilling debt crises and monetary sovereignty," Mimeo

[20] Cruces, J., and C. Trebesch, (forthcoming). "Sovereign defaults: The price of haircuts," American Economic Journal: Macroeconomics

[21] Erce, A., (2012). "Selective sovereign defaults," Federal Reserve Bank of Dallas Working Paper 127

[22] Erce, A., (forthcoming). "Seniority beats growth: The IMF and sovereigns' private creditors," Governance

[23] Gennaioli, N., A. Martin, and S. Rossi, (forthcoming). "Sovereign default, domestic banks, and financial institutions," Journal of Finance

[24] Guembel, A., and O. Sussman, (2009). "Sovereign debt without default penalties," Review of Economic Studies 76, 1297-320 
[25] International Monetary Fund, (2011). Global Financial Stability Report

[26] Lanau, S., (2011). "The contractual approach to sovereign debt restructuring," Bank of England Working Paper 409

[27] Lane, P., (2012). "The European sovereign debt crisis," Journal of Economic Perspectives 26, $49-68$

[28] Lorenzoni, G., and I. Werning, (2013). "Slow moving debt crises," NBER Working Paper 19228

[29] Mendoza, E., and V. Yue, (2012). "A general equilibrium model of sovereign default and business cycles," Quarterly Journal of Economics 127, 889-946

[30] Mengus, E., (2012). "Foreign borrowing, portfolio allocation and bailouts," Mimeo

[31] Merler, S., and J. Pisani-Ferry, (2012). "Who's afraid of sovereign bonds?" Bruegel Policy Contribution 2012/02

[32] Pitchford, R., and M. Wright, (forthcoming). "Strategic behavior in sovereign debt restructuring: Impact and policy responses," in Debt Crises and their Resolution: Analysis and Policies

[33] Reinhart, C., V. Reinhart, and K. Rogoff, (2012). "Public debt overhangs: Advanced-economy episodes since 1800," Journal of Economic Perspectives 26, 69-86

[34] Reinhart, C., and K. Rogoff, (2010). "Growth in a time of debt," American Economic Review PEP 100, 573-8

[35] Roch, F., and H. Uhlig, (2012). "The dynamics of sovereign debt crises and bailouts," Mimeo

[36] Shambaugh, J., (2012). "The euro's three crises," Brookings Papers on Economic Activity Spring 2012, 157-211

[37] Sturzenegger, F., and J. Zettelmeyer, (2007). "Haircuts: Estimating investor losses in sovereign debt restructurings, 1998-2005," Journal of International Money and Finance 27, 780-805

\section{Appendix 1: Taxing investment}

We assume throughout the paper that the government taxes only consumption. This assumption is convenient but it does not affect our main results. Its main implication is that all taxes are paid 
by the old and the impatient young. If the patient young also paid some taxes, their wealth would be reduced and, as a result, so would their investment. To see how this innovation would affect our model, we use $\iota$ to denote the share of taxes that are paid by the patient young. Then, we just need to modify the law of motion as follows:

$$
k_{t+1}= \begin{cases}\min \left\{\frac{\rho}{\rho-\phi} \cdot\left(s \cdot k_{t}^{\alpha}-\iota \cdot x_{t}\right),\left(\frac{\alpha}{(\rho-\phi) / p_{t+1}+\phi+\delta-1}\right)^{\frac{1}{1-\alpha}}\right\} & \text { if } k_{t}<\bar{k}_{t} \\ \min \left\{\frac{\rho}{\rho-\phi} \cdot\left(s \cdot k_{t}^{\alpha}-\iota \cdot x_{t}-d_{t}\right),\left(\frac{\alpha}{\rho+\delta-1}\right)^{\frac{1}{1-\alpha}}\right\} & \text { if } k_{t} \geq \bar{k}_{t}\end{cases}
$$

where $\bar{k}_{t}$ is now defined as:

$$
\frac{\rho}{\rho-\phi} \cdot\left(s \cdot \bar{k}_{t}^{\alpha}-\iota \cdot x_{t}-d_{t}\right)=\left(\frac{\alpha}{(\rho-\phi) / p_{t+1}+\phi+\delta-1}\right)^{\frac{1}{1-\alpha}}
$$

The main difference with Equations (9)-(10) is the appearance of the new term $-\iota \cdot x_{t}$. Taxing the young means that sovereign debt has two effects on investment and growth when compared to the economy without government in Equation (5): the crowding-out effect that we emphasize in the main text and a wealth effect. Both lower investment and growth, for different reasons. The crowding-out effect arises because sovereign debt displaces investment from the portfolio of investors, and its size depends on the importance of discrimination, $p_{t}$. The wealth effect arises because taxation reduces the portfolio of investors, and its size depends on the distribution of taxes, $\iota$. Thus, adding taxes on investment reinforces the notion that sovereign debt reduces investment and growth.

\section{Appendix 2: Sovereign debt as collateral}

In this appendix, we show that nothing substantial changes if sovereign debt can also be pledged as collateral. Assume, for instance, that the credit constraint of Equation (4) is given by:

$$
f_{t} \leq \frac{\phi \cdot\left(k_{t+1}+d_{t}\right)}{\rho}
$$


In this case, we have that the law of motion takes the following form:

$$
k_{t+1}= \begin{cases}\min \left\{\frac{\rho}{\rho-\phi} \cdot s \cdot k_{t}^{\alpha},\left(\frac{\alpha}{\rho / p_{t+1}+\delta-1}\right)^{\frac{1}{1-\alpha}}\right\} & \text { if } k_{t}<\bar{k}_{t} \\ \min \left\{\frac{\rho}{\rho-\phi} \cdot s \cdot k_{t}^{\alpha}-d_{t},\left(\frac{\alpha}{\rho+\delta-1}\right)^{\frac{1}{1-\alpha}}\right\} & \text { if } k_{t} \geq \bar{k}_{t}\end{cases}
$$

where $\bar{k}_{t}$ is now defined as follows:

$$
\frac{\rho}{\rho-\phi} \cdot s \cdot \bar{k}_{t}^{\alpha}-d_{t}=\left(\frac{\alpha}{\rho / p_{t+1}+\delta-1}\right)^{\frac{1}{1-\alpha}}
$$

There are two key differences with Equations (9)-(10) in the main body of the paper. The first is that $\phi$ no longer shows up in the first flat of the law of motion, $\left(\frac{\alpha}{\rho / p_{t+1}+\delta-1}\right)^{\frac{1}{1-\alpha}}$. The reason is that, once capital and debt can be equally pledged as collateral, $\phi$ does not affect the relative return of both assets. The second difference is that $d_{t}$ is no longer pre-multiplied by $\frac{\rho}{\rho-\phi}$. This reflects the assumption that investors can borrow against the debt they hold, which provides additional resources for investment. These are the only changes to our baseline model and they do not affect any of our main results.

\section{Appendix 3: Long-term bonds}

In this appendix, we examine the implications of having different types of debt. We start by assuming that there are two types of debt: (i) a short-term bond issued in period $t$ at price one that promises a payment $R_{t+1}^{S}$ in period $t+1$; and (ii) a long-term bond issued in period $t$ also at price one that promises a payment of $R_{t+2}^{L}$ in period $t+2$. We define $q_{t+1}$ as the price of this long-term bond one period before maturity (or one period after issuance). As usual, defaulting on short-term bonds automatically implies default on long-term bonds.

Assume first that the government defaults on both domestic and foreign creditors, i.e. $p_{t}^{F}=$ $p_{t}^{D}=0$. This means that all bonds held by domestic and foreign creditors become worthless. This implies that:

$$
R_{t+1}^{S}=q_{t+1}=\frac{R_{t+1}^{L}}{q_{t}}=\frac{\rho}{p_{t+1}}
$$

In period $t$, creditors can choose among short-term bonds and long-term bonds that mature in periods $t+1$ and $t+2$. Equation (27) says that all these bonds must offer the same expected return 
and, since the international financial market is risk-neutral, this expected return must equal the interest rate $\rho$. Under these circumstances, all bonds are perfect substitutes from the perspective of both domestic and foreign creditors. The presence of different maturities does not change the analysis, and the law of motion of the economy is still given by Equation (5). Thus, in the absence of discrimination, introducing long-term bonds does not affect the dynamics of the economy.

Assume now that the government defaults on foreign creditors only, i.e. $p_{t}^{F}=0$ and $p_{t}^{D}=1-p_{t}$. This means that all bonds held by foreign creditors become worthless. What happens to the different bonds held by domestic creditors in a default? In the main text, there are only short-term bonds and we make the assumption that domestic creditors receive the contractual rate $R_{t+1}^{S}$. A natural assumption would be that long-term bonds that mature in the same period are also paid the contractual rate $R_{t+1}^{L}$. This means that all maturing bonds held by domestic creditors are perfect substitutes and, as a result, we have that:

$$
R_{t+1}^{S}=\frac{R_{t+1}^{L}}{q_{t}}=\min \left\{\frac{\rho}{p_{t+1}},\left(\alpha \cdot k_{t+1}^{\alpha-1}+1-\delta-\phi\right) \cdot \frac{\rho}{\rho-\phi}\right\}
$$

Equation (28) says that, if the return to investment net of financing costs exceeds the expected return on maturing bonds, the domestic private sector does not buy the maturing debt and the marginal buyer is a foreign creditor. If instead the return to investment net of financing costs falls short of the expected return on maturing bonds, the domestic private sector buys the maturing debt and the marginal buyer is a domestic creditor.

What happens to non-maturing bonds held by domestic creditors in a default? Let $v_{t+1}$ be the price that these creditors receive as a share of the price that these bonds would have had in the absence of default. Then, we have that:

$$
q_{t+1}=\min \left\{\frac{\rho}{p_{t+1}}, \frac{\alpha \cdot k_{t+1}^{\alpha-1}+1-\delta-\phi}{1+\left(1-p_{t+1}\right) \cdot\left(v_{t+1}-1\right)} \cdot \frac{\rho}{\rho-\phi}\right\}
$$

Equation (29) is analogous to Equation (28). It says that if the return to investment net of financing costs exceeds the expected return on non-maturing bonds, the domestic private sector does not buy the non-maturing bonds and the marginal buyer is a foreign creditor. If instead the return to investment net of financing costs falls short of the expected return on non-maturing bonds, the domestic private sector buys the maturing bonds and the marginal buyer is a domestic creditor. 
If $v_{t+1}=1$, domestic creditors receive the same from these bonds regardless of whether or not there is a default. Maturing and non-maturing bonds are thus treated equally and, as a result, they become perfect substitutes and their expected returns are equalized always. In this case, introducing long-term bonds does not affect the analysis in the main text. In particular, the law of motion is still given by Equations (9)-(10). This confirms that our model is unaffected by the maturity structure of debt under two conditions: (i) when the government defaults, it does so simultaneously on all maturities, and; (ii) in the event of a default, bonds of all maturities are treated equally.

The introduction of different maturities only affects the analysis if they are treated asymmetrically in the event of a default. Assume, for instance, that non-maturing bonds are paid at face value, i.e. $R_{t+2}^{L}$ if the default occurs in period $t+1$. It follows that $v_{t+1}=R_{t+2}^{L} \cdot q_{t+1}^{-1}>1$, because the bond pays at face value but one period before the original maturity. This means that nonmaturing bonds are treated better than maturing bonds in the event of a default and, as a result, they are more attractive to domestic creditors. Under this assumption, the law of motion becomes:

$$
k_{t+1}= \begin{cases}\min \left\{\frac{\rho}{\rho-\phi} \cdot s \cdot k_{t}^{\alpha},\left(\frac{\alpha}{(\rho-\phi) \cdot\left[1+\left(1-p_{t+1}\right) \cdot\left(v_{t+1}-1\right)\right] / p_{t+1}+\phi+\delta-1}\right)^{\frac{1}{1-\alpha}}\right\} & \text { if } k_{t} \leq \underline{k}_{t} \\ \min \left\{\frac{\rho}{\rho-\phi} \cdot\left(s \cdot k_{t}^{\alpha}-d_{t}^{N}\right),\left(\frac{\alpha}{(\rho-\phi) / p_{t+1}+\phi+\delta-1}\right)^{\frac{1}{1-\alpha}}\right\} & \text { if } \underline{k}_{t}<k_{t}<\bar{k}_{t} \\ \min \left\{\frac{\rho}{\rho-\phi} \cdot\left(s \cdot k_{t}^{\alpha}-d_{t}\right),\left(\frac{\alpha}{\rho+\delta-1}\right)^{\frac{1}{1-\alpha}}\right\} & \text { if } k_{t} \geq \bar{k}_{t}\end{cases}
$$

where $d_{t}^{N}$ is the non-maturing debt and $\underline{k}_{t}$ and $\bar{k}_{t}$ are defined as:

$$
\begin{gathered}
\frac{\rho}{\rho-\phi} \cdot\left(s \cdot \underline{k}_{t}^{\alpha}-d_{t}^{N}\right)=\left(\frac{\alpha}{(\rho-\phi) \cdot\left[1+\left(1-p_{t+1}\right) \cdot\left(v_{t+1}-1\right)\right] / p_{t+1}+\phi+\delta-1}\right)^{\frac{1}{1-\alpha}} \\
\frac{\rho}{\rho-\phi} \cdot\left(s \cdot \bar{k}_{t}^{\alpha}-d_{t}\right)=\left(\frac{\alpha}{(\rho-\phi) / p_{t+1}+\phi+\delta-1}\right)^{\frac{1}{1-\alpha}}
\end{gathered}
$$

The main difference with Equations (9)-(10) is the appearance of an additional step in the crowdingout region. The intuition is simple. If $k_{t} \leq \underline{k}_{t}$ domestic creditors purchase only non-maturing debt, if any, because the return to investment is high. If $\underline{k}_{t}<k_{t}<\bar{k}_{t}$ the return to investment is lower and domestic creditors purchase the entire stock of non-maturing debt along with some maturing debt. If $k_{t} \geq \bar{k}_{t}$, the return to investment is so low that domestic creditors purchase the entire stock of debt, both maturing and non-maturing. In this particular example, then, long-term debt 
enlarges the crowding-out region and thus the crisis zone.

\section{Appendix 4: Data description}

To support the analysis on the paper, whenever possible, we collected a database comprising seven euro-area countries (Germany, France, Italy, Spain, Portugal, Ireland and Greece) for the period 2000-2012. Almost all data series cover the full sample period, but a few cover only until 2010. The data contains information on GDP and GDP growth, spreads, public debt and deficits and their components, banks' allocation of credit by sector, sovereign debt holdings by residence and sector, and public debt maturity structure. The data on nominal GDP used throughout the empirical part was obtained from Eurostat. A detailed description of the rest of the data sources is presented in what follows.

Spreads: We collected data on public and private spreads. The spreads equal the difference in yield between the corresponding bond and the German reference Bund. For figures 1,4 and 6, we used quarterly data on 10-year sovereign spreads coming from Datastream. Sovereign spreads in Figure 8 were obtained from Haver Analytics and correspond to 5 -year sovereign bonds. Information on private-sector spreads was derived separately for corporates and households. Data on yields on corporate loans and consumption loans for households also come from Haver Analytics. Corporate yields refer to loans above 1 million euro and maturities between 1 and 5 years for all countries but Greece, where long time series were only available for loans of maturities up to one year, and Ireland and Portugal, where loans of all maturities are pooled. Household yields refer to loans with maturities between 1 and 5 years for all sample countries. Private spreads are calculated against the benchmark 5-year German Bund. All spreads presented in Figures 1, 4, 6 and 8, are measured in basis points (Bps).

Public debt, public deficit and subcomponents: Figure 2 represents a decomposition of both public debt and deficits. Data, on an annual basis, was obtained from the OECD's Economic Outlook Database. More specially, from this source we gathered the following general-government series: financial balance; cyclically-adjusted balance; underlying balance adjusted for the cycle and oneoffs; underlying primary balance adjusted for the cycle and one-offs and excluding net interest payments (i.e. the structural primary balance), net debt interest payments, and gross financial liabilities (i.e. public debt). Using these variables, we calculated the general government primary 
balance by subtracting net debt interest payments from the financial balance. Additionally, we disaggregated the primary balance into the structural primary balance component (underlying primary balance) and the cyclical primary balance component. The cyclical primary balance was derived by subtracting from the primary balance the underlying primary balance and one-offs. Oneoffs, in turn, are the difference between underlying balance and cyclically-adjusted balance. The other adjustments category was obtained by subtracting the interest component, growth component, cyclical component and structural component from the change in public debt.

Government debt maturity structure: In order to gauge the relevance of public debt maturity we collected data on government debt average term to maturity (top panel of Figure 3) and short-term debt as a percent of total debt (bottom panel of Figure 3). The data on average term to maturity comes from the OECD and the Irish Treasury for Ireland, from the OECD for Germany, from the Ministry of Finance for Spain, and from the European Central Bank for France, Portugal, Italy, and Greece. The OECD's dataset ends in 2010. For Ireland we recovered the missing data using the Treasury's 2012 Annual Report. Unfortunately, we could not obtain analogous information for Germany. Short-term debt refers to gross government debt with residual maturities up to one year. The term government debt refers to general government debt for all countries except Ireland, where it refers to central government debt. End-of-year data for Germany, France, Spain, Greece, Italy and Portugal comes from the European Central Bank. Quarterly data for Ireland comes from the Central Bank of Ireland. ${ }^{38}$

Sovereign debt holdings: In order to understand the nationality of the agents holding the outstanding sovereign debt we resorted to a variety of sources feeding from our sample-countries Central Banks. We combined various sources as our interest was in obtaining, whenever possible, information regarding nominal holdings, avoiding mark to market measures which can be significantly affected by price dynamics. ${ }^{39}$ More specifically, data on sovereign debt holdings of Germany, Greece, Ireland and Italy comes from Merler and Pisani-Ferry (2012). In turn, data on sovereign debt holdings for France and Spain come from the corresponding Central Banks and for Portugal from Andritzky (2012) and the European Central Bank. Unfortunately the definition of sovereign debt is not homogeneous among countries. Sovereign debt holdings refer to central government

\footnotetext{
${ }^{38}$ Specifically, we used the Statistical Appendix - Section E - Table E.1 Government Debt, from the Irish Central Bank Quarterly Bulletin.

${ }^{39}$ Actually, the data is nominal value for all countries but Greece where, according to the Bank of Greece, it mixes market and nominal values.
} 
OATs (medium-long term securities) for France, to general government debt for Germany, to central government long term bonds for Ireland, and to central government securities for Spain, Greece, Italy and Portugal. As shown in Figure 5, the data on holdings by residents comes disaggregated by different economic agents. In order to present the data using a foreign-domestic divide, as in Figure 4, we added together the corresponding categories of resident debtholders. ${ }^{40}$

Allocation of bank credit by sector: In order to understand the allocation of credit among the different economic sectors we resorted to each country's National Central Banks' Monetary Surveys. From these surveys we obtained data on bond holdings and loan provisioning by banks vis-a-vis the following sectors: non-financial corporations, households and the public sector. In order to get the total credit exposure by sector we added the information on bond holdings and loans provided to each sector. The data was collected on a monthly format for Germany, France, Italy and Greece, and on a quarterly fashion for Spain, Ireland and Portugal. We used quarterly data on nominal GDP from Eurostat to calculate bank credit as percentage of GDP. This set of data was used to construct Figures 7 and 8. While Figure 7 simply depicts our credit series by sector, Figure 8 presents a ratio of public-sector credit to private-sector credit. We derived such ratio by dividing credit to the general government (loans plus bonds) by the sum of credit to non-financial corporations (bonds plus loans) and credit to households (loans). In France, the existing data for monetary financial institutions prevented us from separating data on loans for households and non-financial corporations. For that reason we used instead information for credit institutions.

\footnotetext{
${ }^{40}$ For Ireland and Spain the data on holdings by financial institutions includes the Central Bank.
} 
Figure 1. A bird's eye view of the Euro periphery

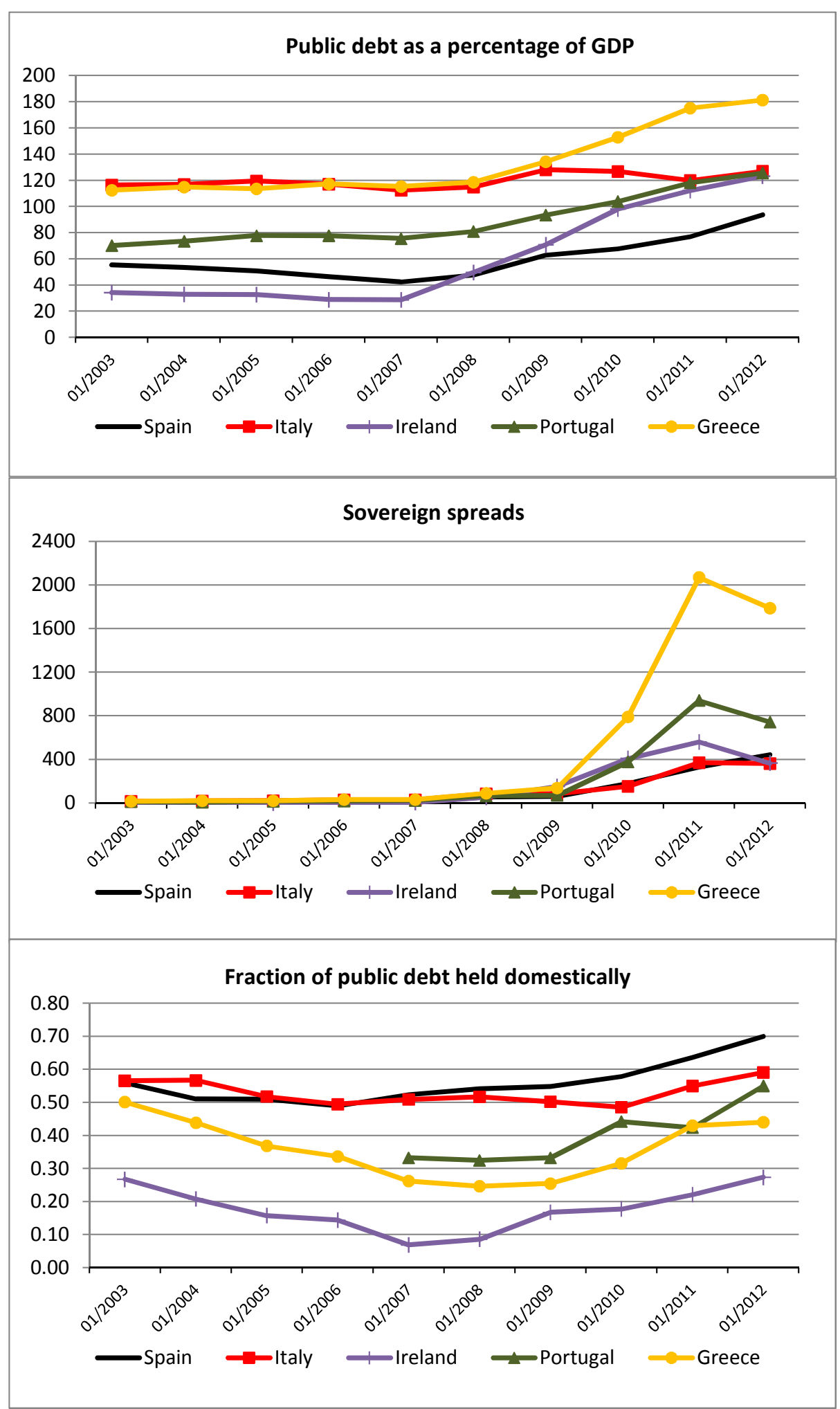

Data on gross public liabilities comes from the OECD. Data on spreads, measured in basis points, refers to the spread against the 10 year German Bund and was obtained from Datastream. Data on sovereign debt holdings comes from our sample countries' Central Banks and Merler and Pisani-Ferry (2012). 
Figure 2. Public debt and deficit

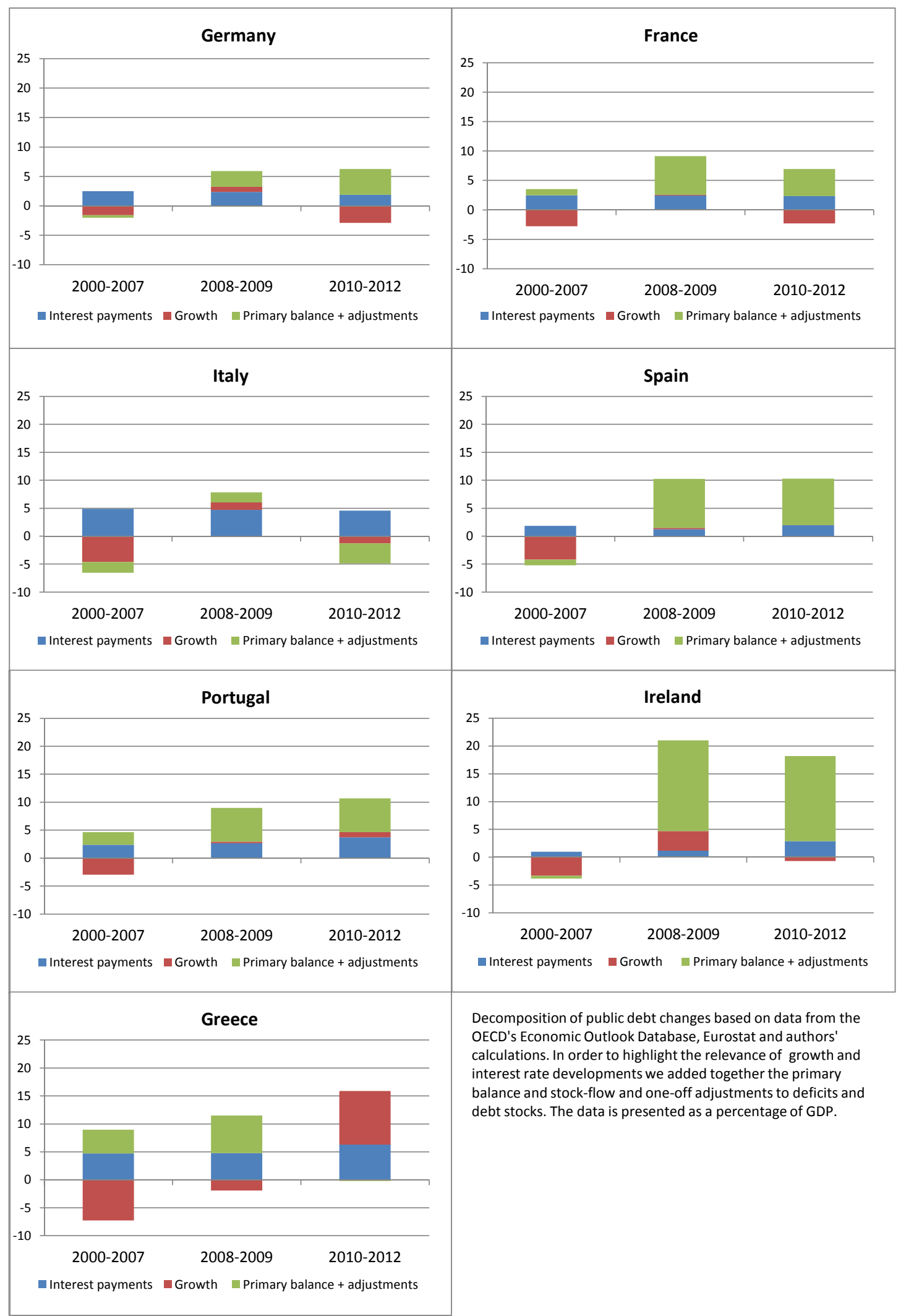


Figure 3. Sovereign debt maturity structure

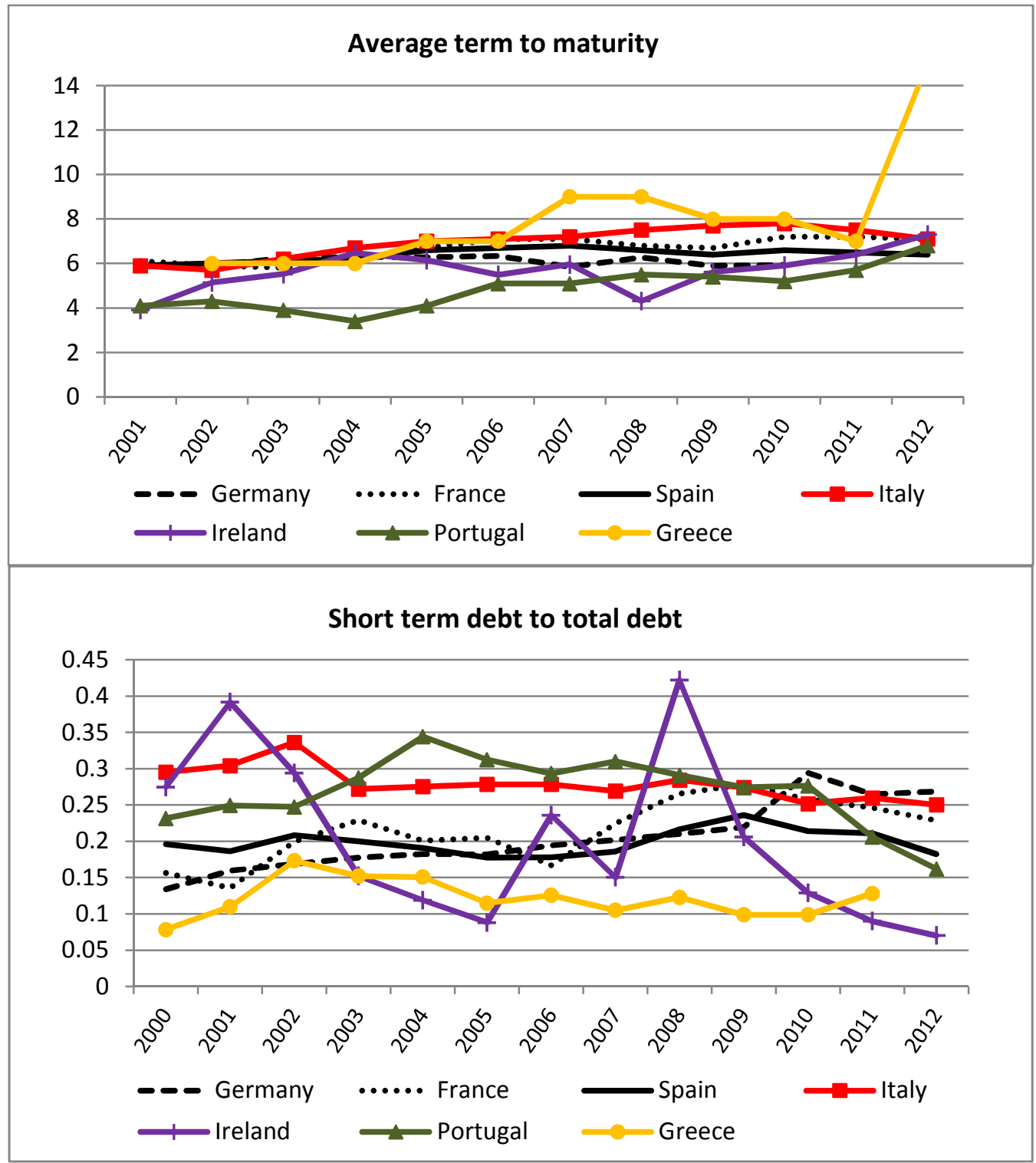

Average term maturity data comes from the OECD and Central Bank of Ireland for Ireland and Germany, and the Spanish Treasury for Spain. For the other sample-countries we used ECB data on average residual maturity. Government short-term debt is government debt with maturity up to 1 year. Short term debt data comes from the ECB for all of our samplecountries but Ireland, for which data coming from the Central Bank of Ireland was used. 
Figure 4. Resident and foreign holdings of sovereign debt

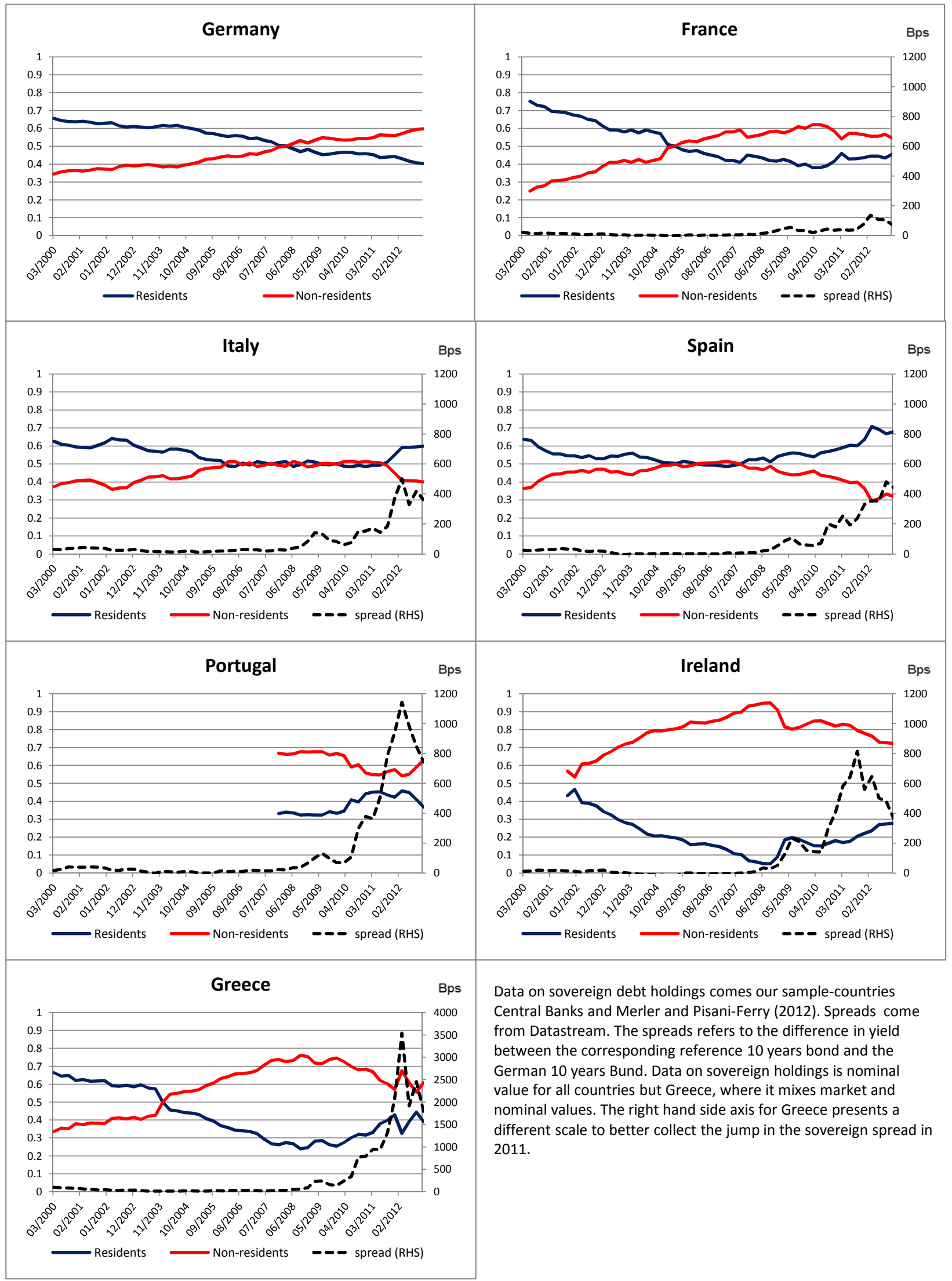


Figure 5. Residents' sovereign debt holdings by sector

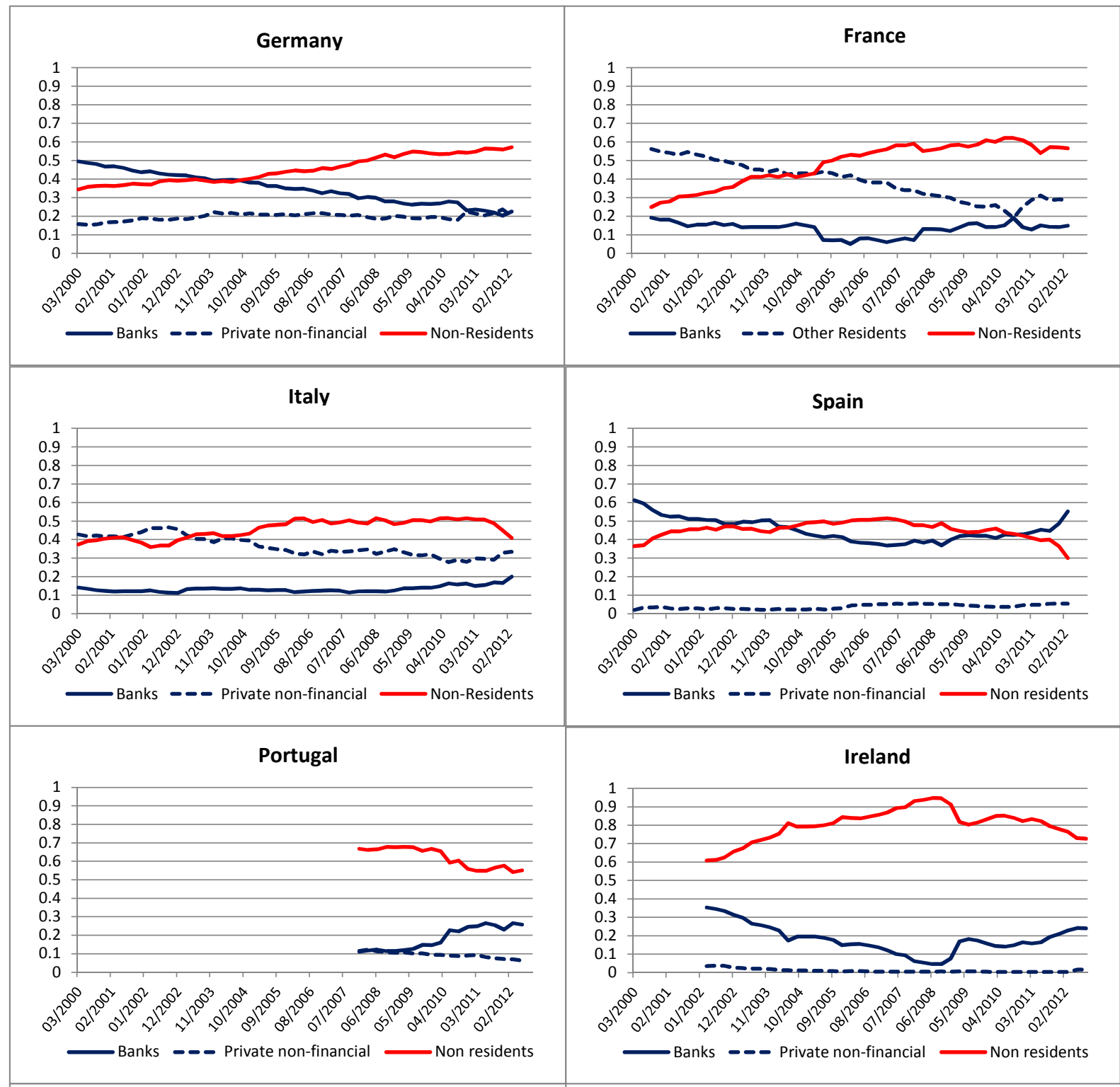

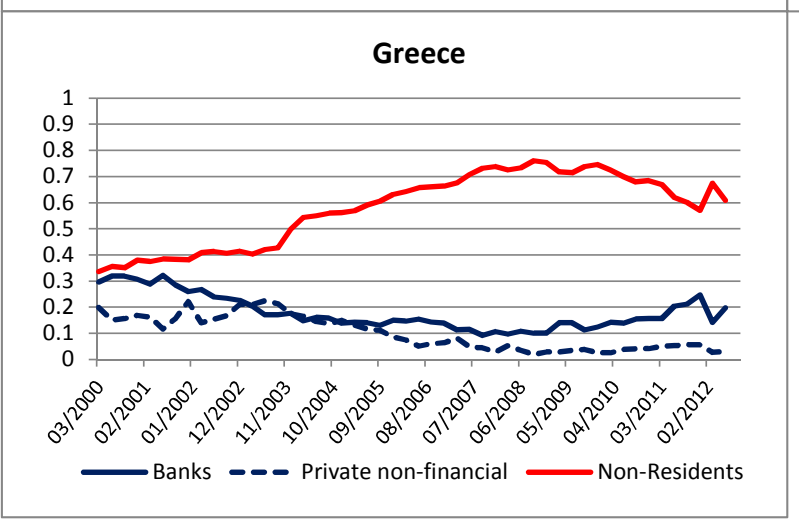

Data comes from our sample-countries' Central Banks and Merler and Pisani-Ferry (2012). The vertical axis measures the ratio of each domestic sector's holdings to the total outstanding. For all countries but France, we show two components of residents' holdings, banks' holdings and private non-financial holdings, which equals holdings by households and firms. For France the breakdown available prevented us from disentangling public sector's holdings from private non financial holdings. 
Figure 6. Credit allocation

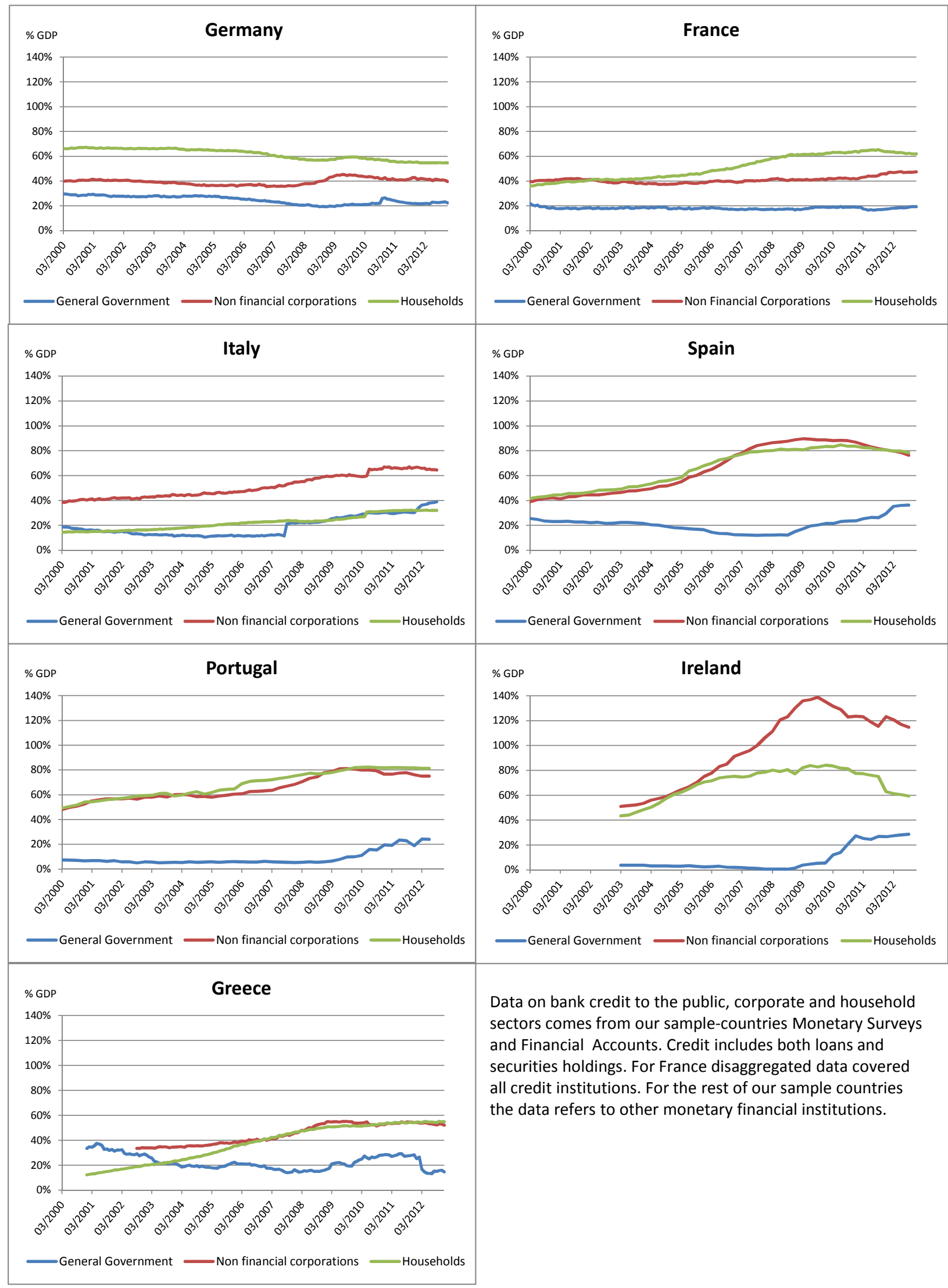


Figure 7. Private versus public credit and sovereign spreads
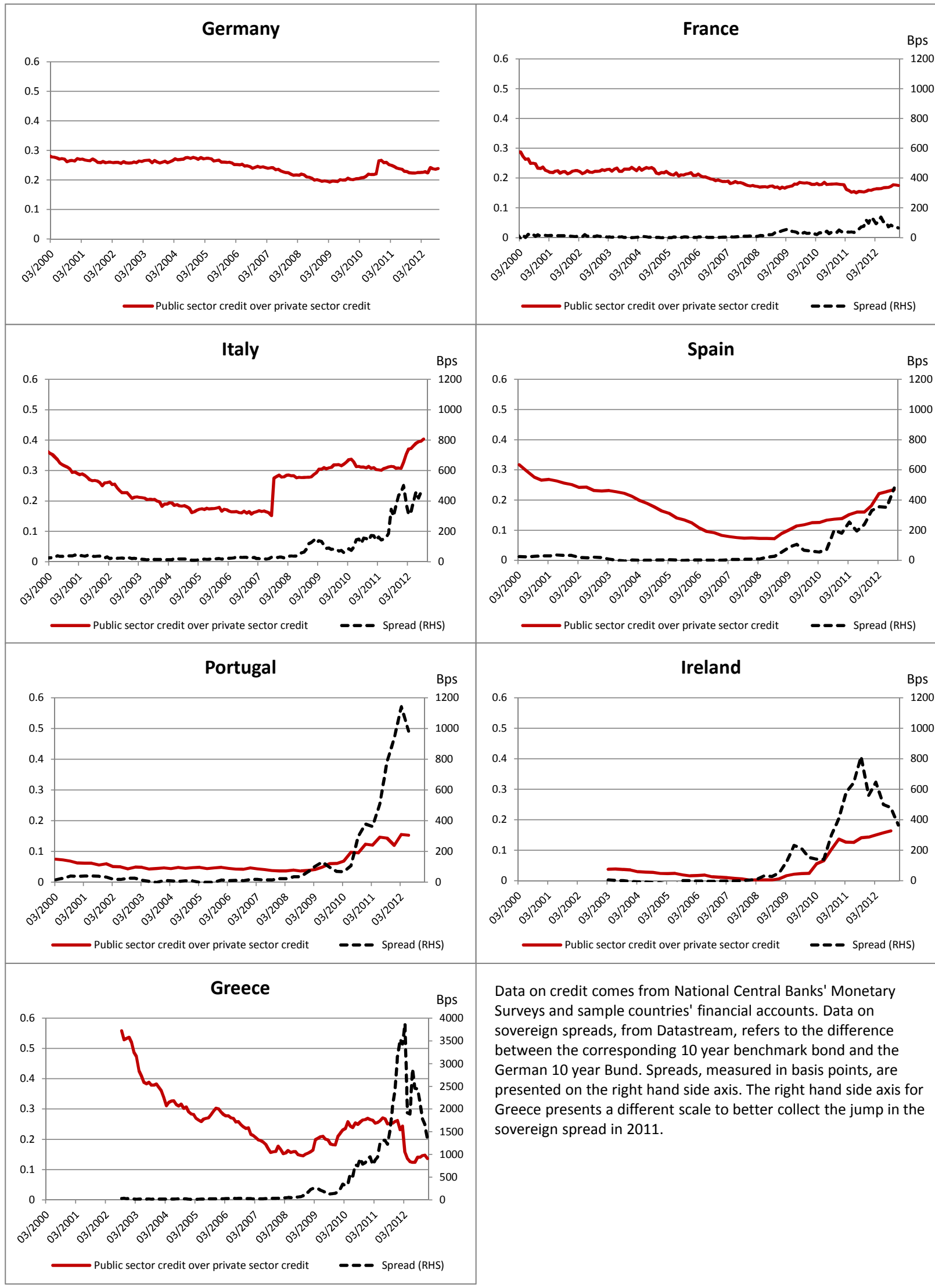

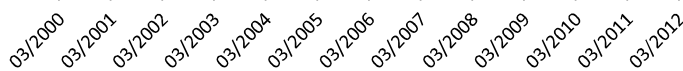

Public sector credit over private sector credit _ _ _ Spread (RHS)

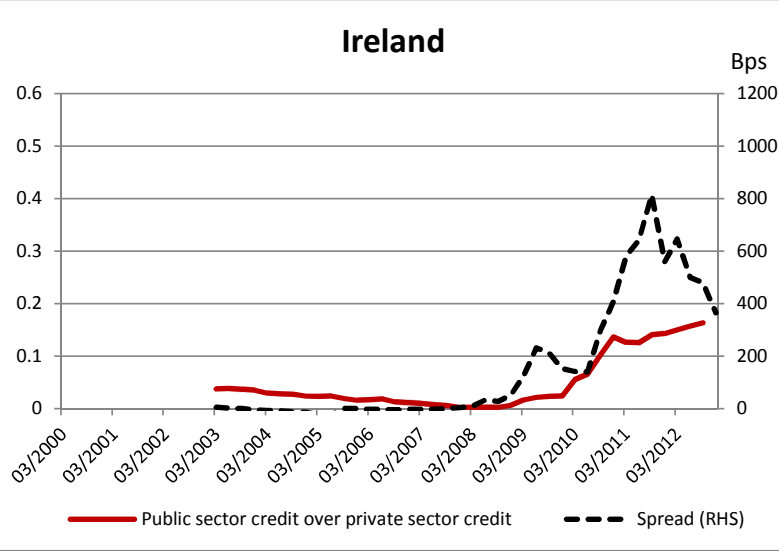

Data on credit comes from National Central Banks' Monetary Surveys and sample countries' financial accounts. Data on sovereign spreads, from Datastream, refers to the difference between the corresponding 10 year benchmark bond and the German 10 year Bund. Spreads, measured in basis points, are presented on the right hand side axis. The right hand side axis for Greece presents a different scale to better collect the jump in the sovereign spread in 2011. 
Figure 8. Sovereign and private spreads

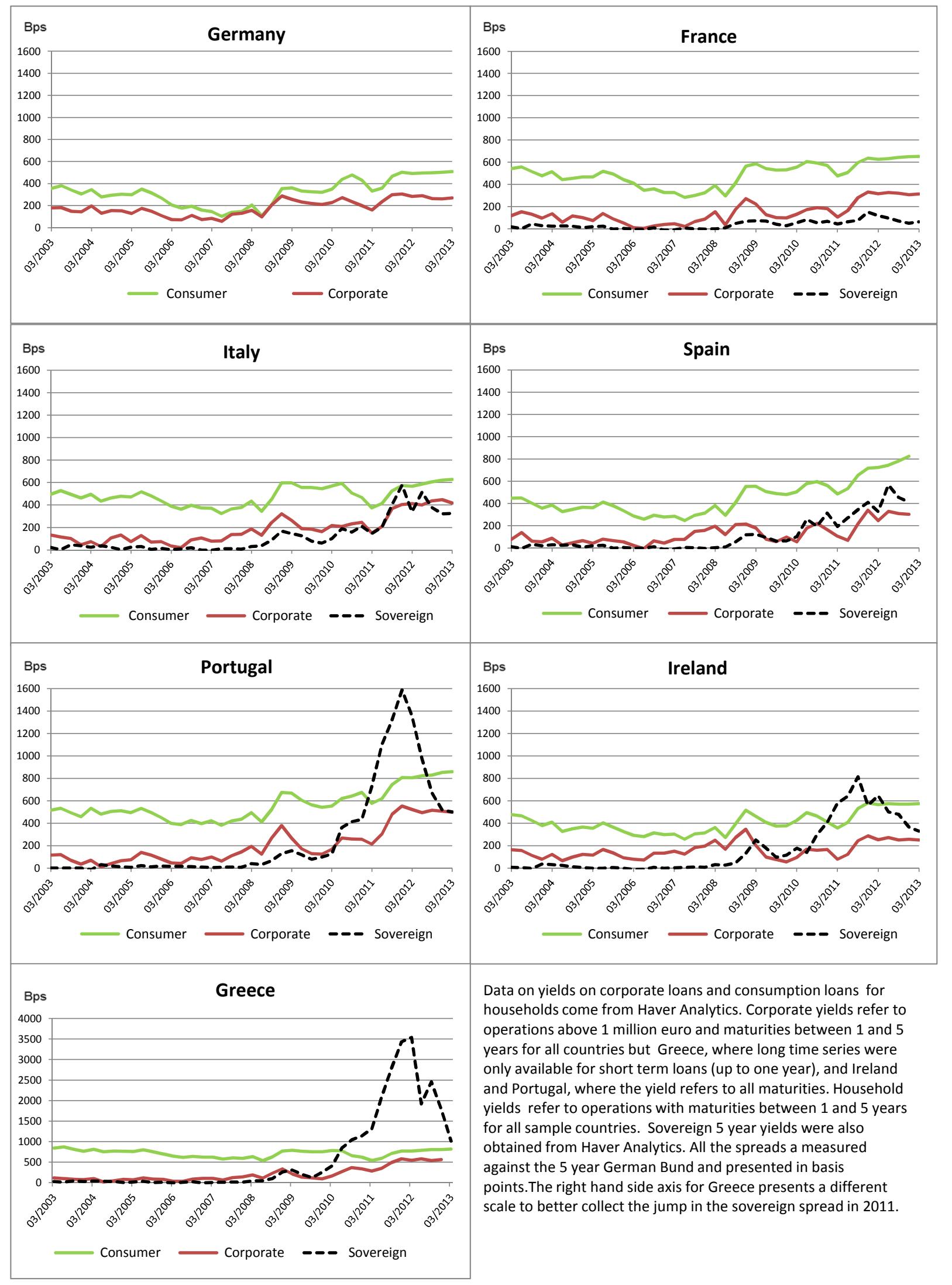


Figure 9: The law of motion with and without discrimination

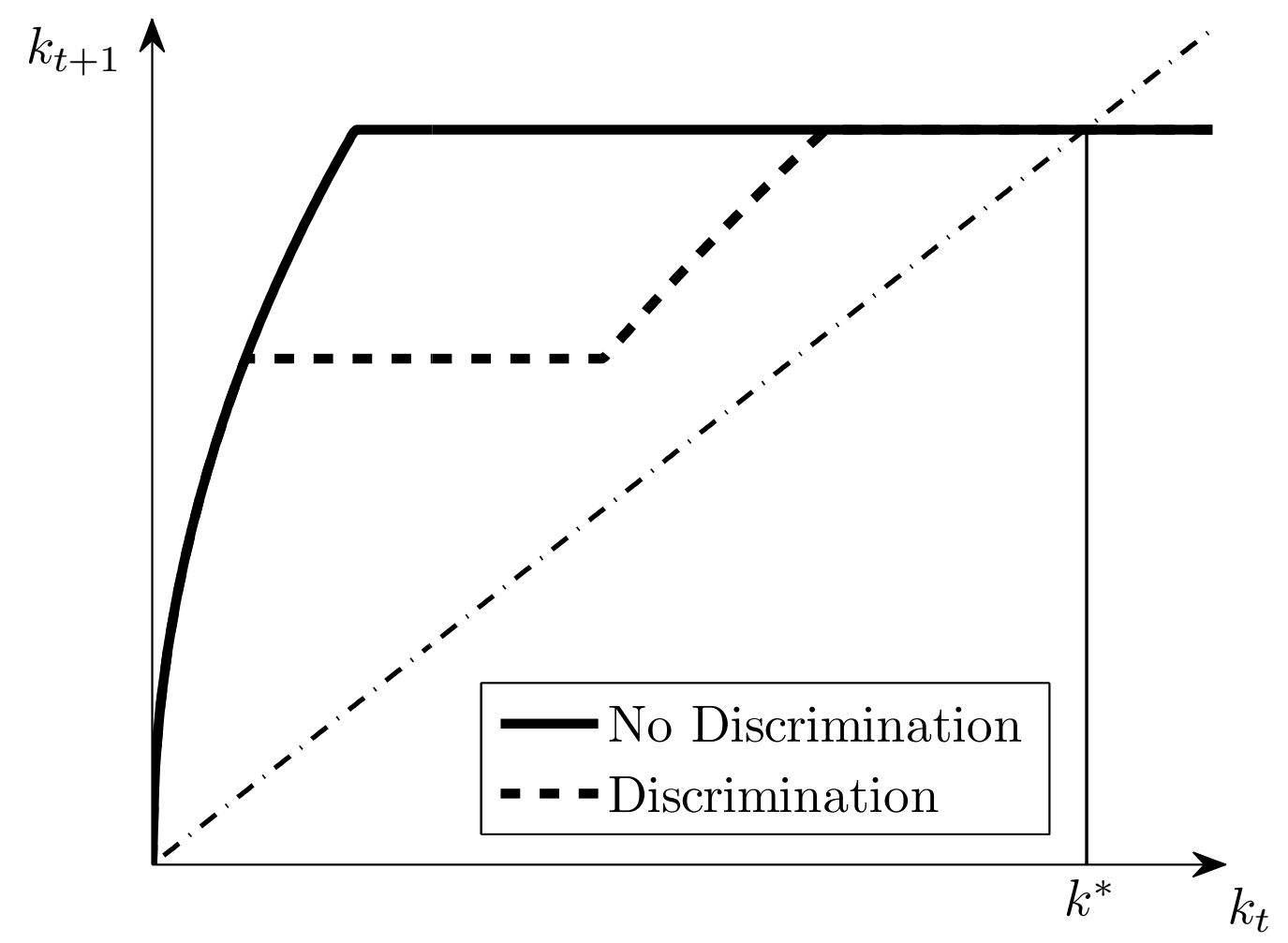

The solid line shows the law of motion of the capital stock when there is no discrimination between foreign and domestic creditors. It is defined by Equation (5). The dashed line shows the law of motion of the capital stock when default affects only foreign creditors, and is defined by Equations (9) and (10). The dash-dot line is the $45^{\circ}$ line. 
Figure 10: The effects of changes in debt and repayment probability
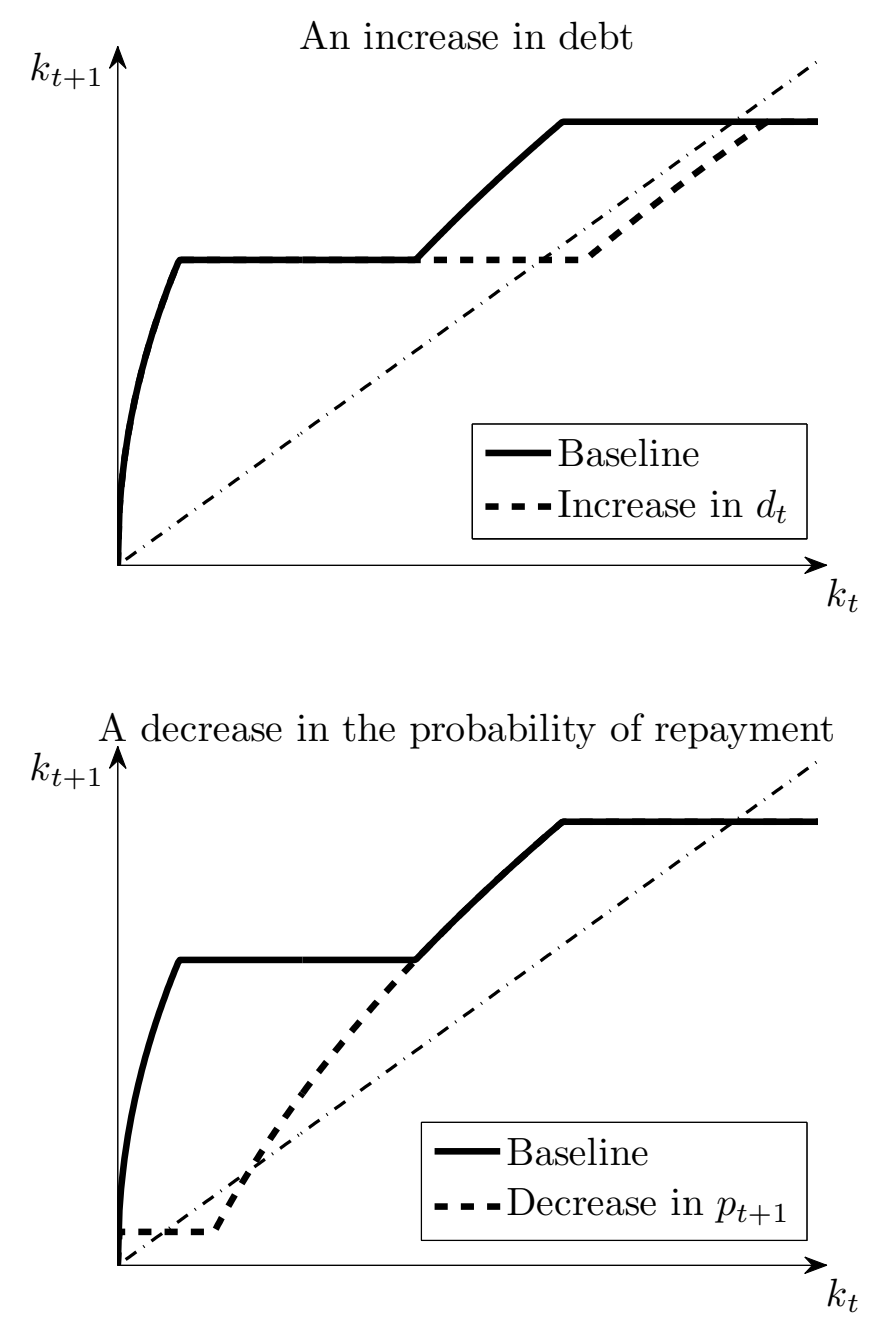

In both panels, the solid line shows the law of motion of the capital stock when default affects only foreign creditors, as defined by Equations (9) and (10). The dashed line shows the same law of motion when changing one parameter value: in the top panel, $d_{t}$ increases and in the bottom panel, $p_{t+1}$ decreases. The dash-dot line in both panels is the $45^{\circ}$ line. 


\section{Figure 11: Crowding-out effects and dynamics}
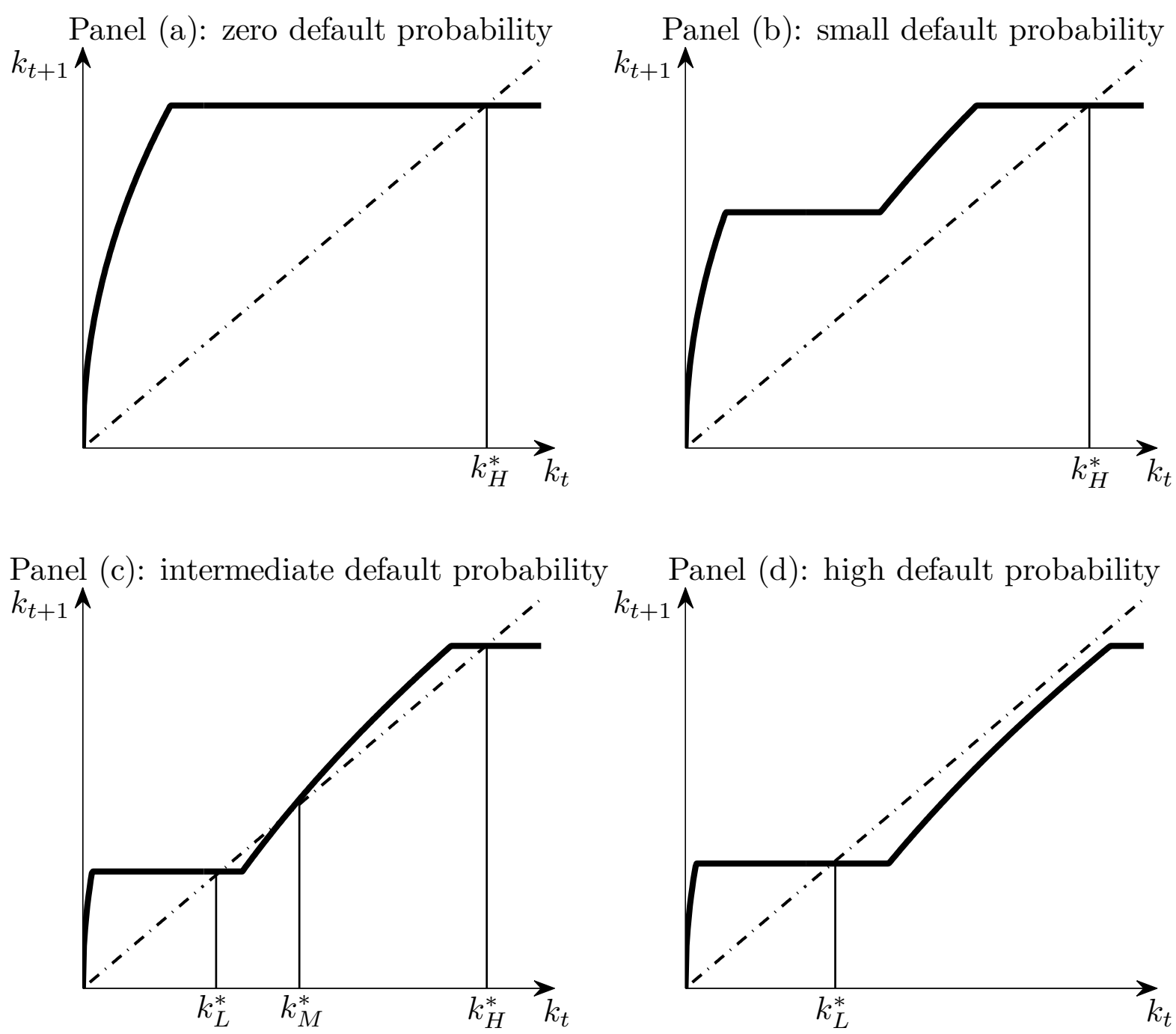

The solid line in the four panels shows the law of motion of the capital stock as defined by Equations (9) and (10), modified by taking into account Equation (14). Moving from Panel (a) to Panel (d), the probability of default $p_{t+1}$ is gradually increased. In Panels (c) and $(\mathrm{d})$, the debt level $d$ is also slightly higher than in Panels (a) and (b). The dash-dot line in all panels is the $45^{\circ}$ line. 
Figure 12: The law of motion with multiple equilibria

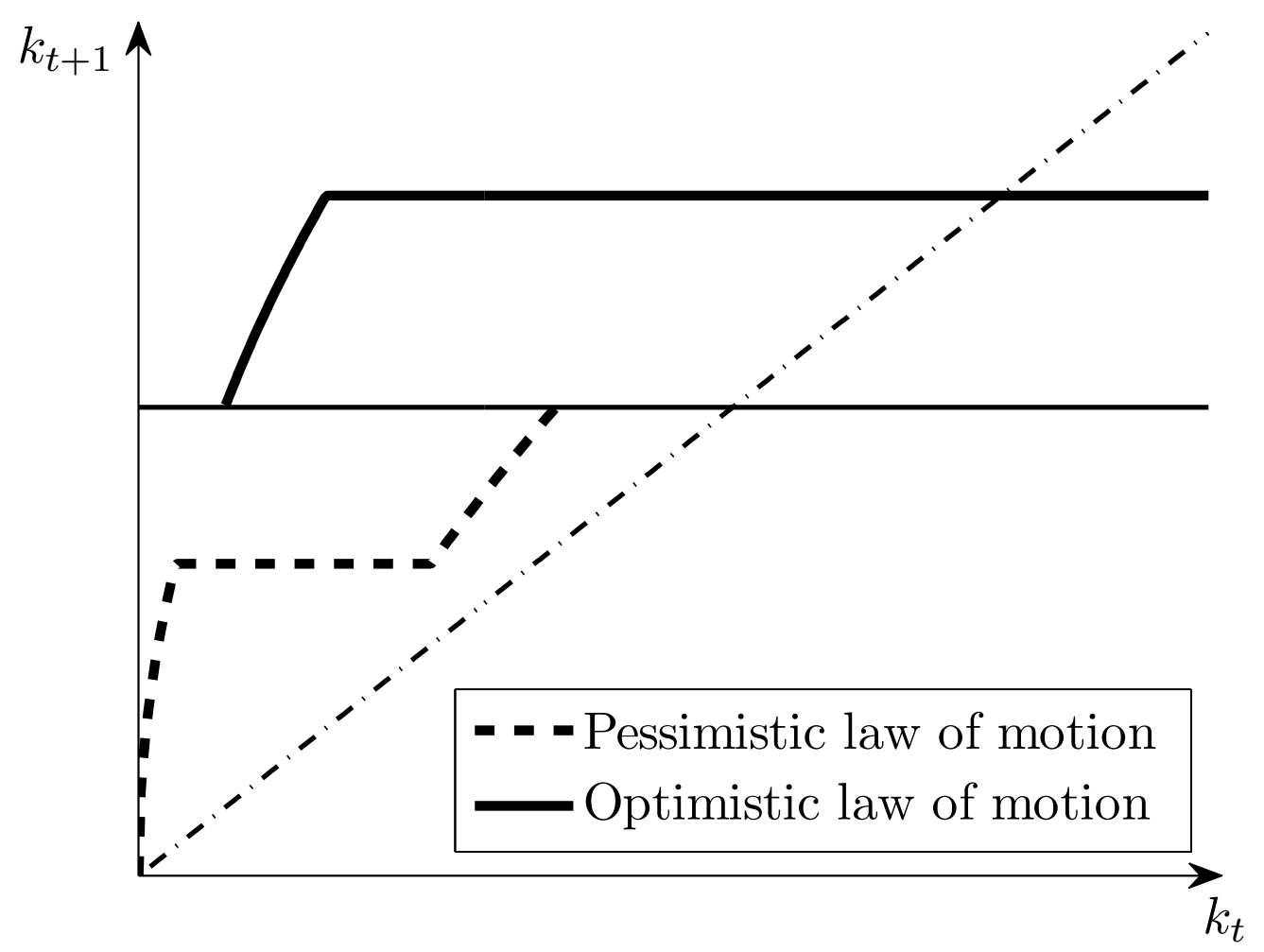

The solid line represents the optimistic law of motion as defined by Equation (17). The dotted line represents the pessimistic law of motion as defined by Equation (19). The dash-dot line is the $45^{\circ}$ line. 


\section{Figure 13: Dynamics with crisis zones}
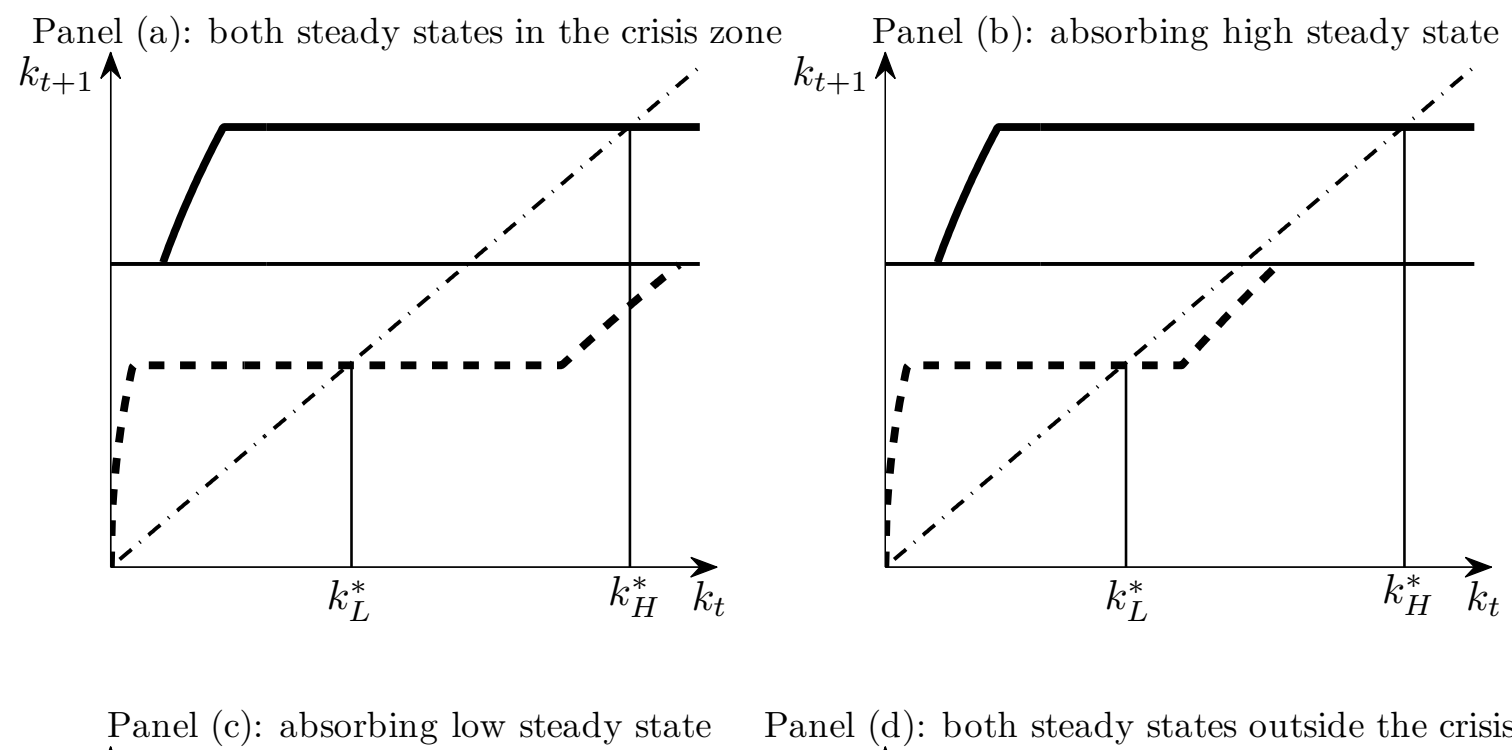

Panel $(\mathrm{d})$ : both steady states outside the crisis zone
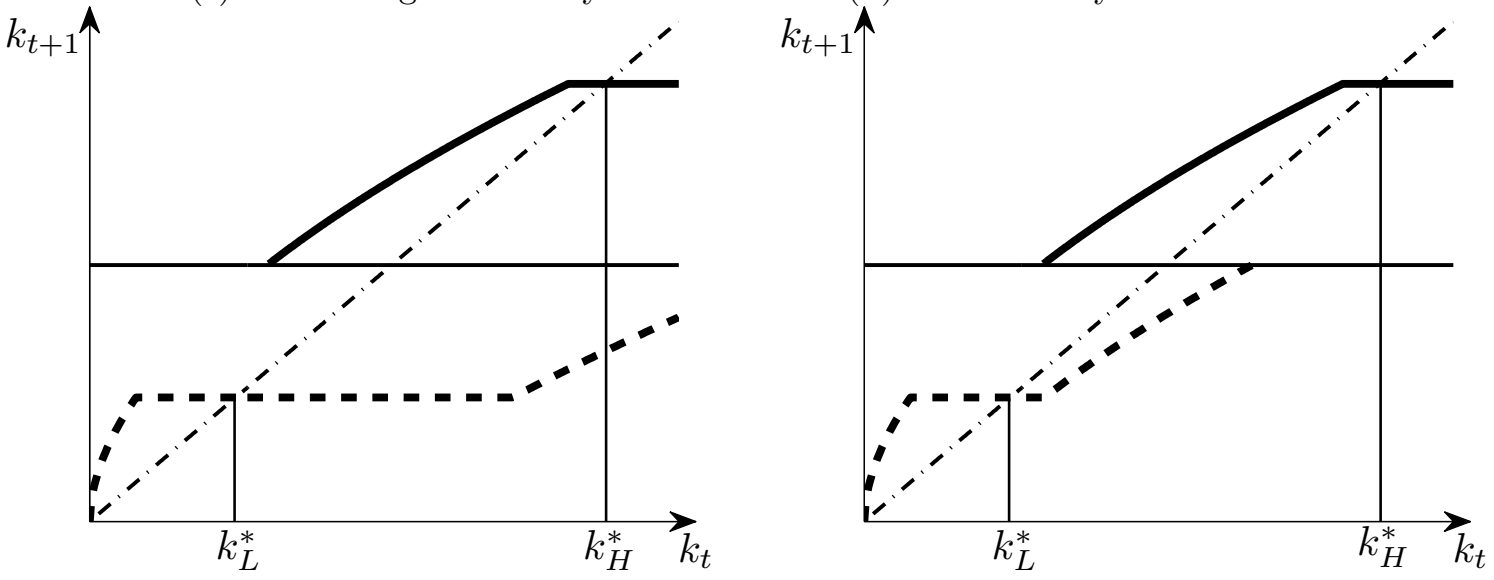

In all panels, the solid line represents the optimistic law of motion as defined by Equation (17), and the dotted line represents the pessimistic law of motion as defined by Equation (19). In panels (a) and (c), the debt level is high, so that both the optimistic and the pessimistic equilibrium exist at the high steady state. In panels (b) and (d), the debt level is lower, so that only the optimistic equilibrium exists at the high steady state. Furthermore, in panels (b) and (d), the curvature of the law of motion (governed by the parameters $\alpha$ and $\phi$ ) is higher. In all panels, the dash-dot line is the $45^{\circ}$ line. 
Figure 14: The effects of joining an economic union

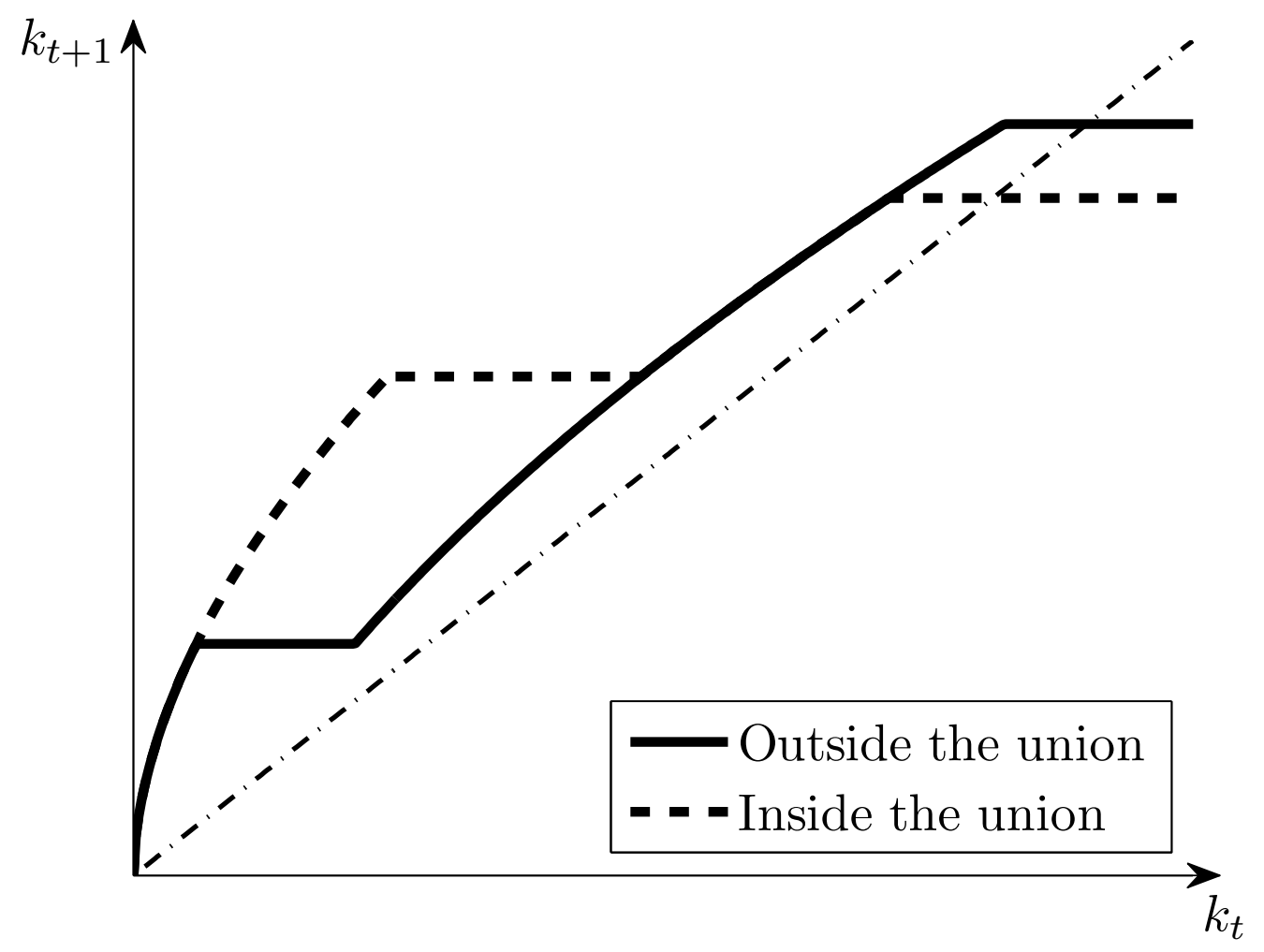

The solid line represents the low of motion of the capital stock outside the economic union, as defined by Equations (9) and (10). The dotted line represents the law of motion of the capital stock inside the economic union, as defined by Equations (22) and (23). The dash-dot line is the $45^{\circ}$ line. 


\section{Figure 15: Dynamics of an economic union}

Panel (a): Low debt, low breakup probability

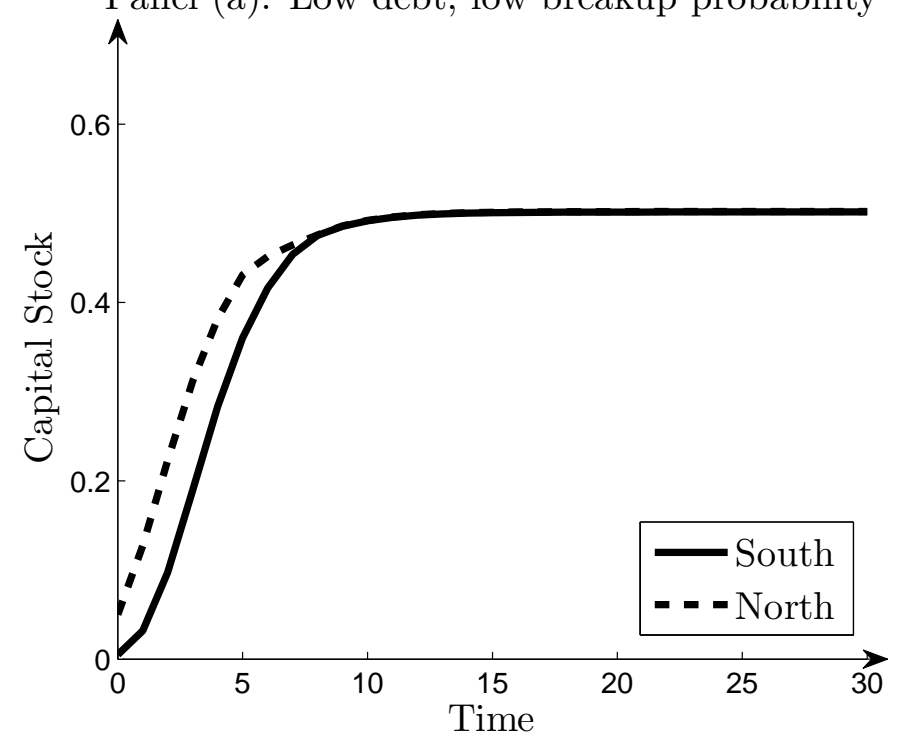

Panel (c): High debt, low breakup probability

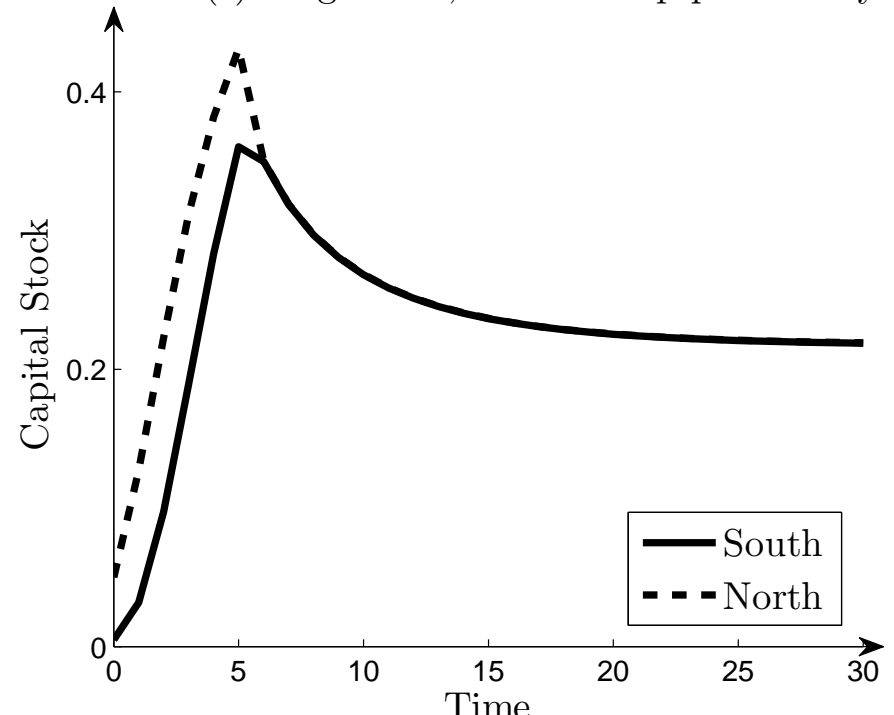

Panel (b): Low debt, high breakup probability

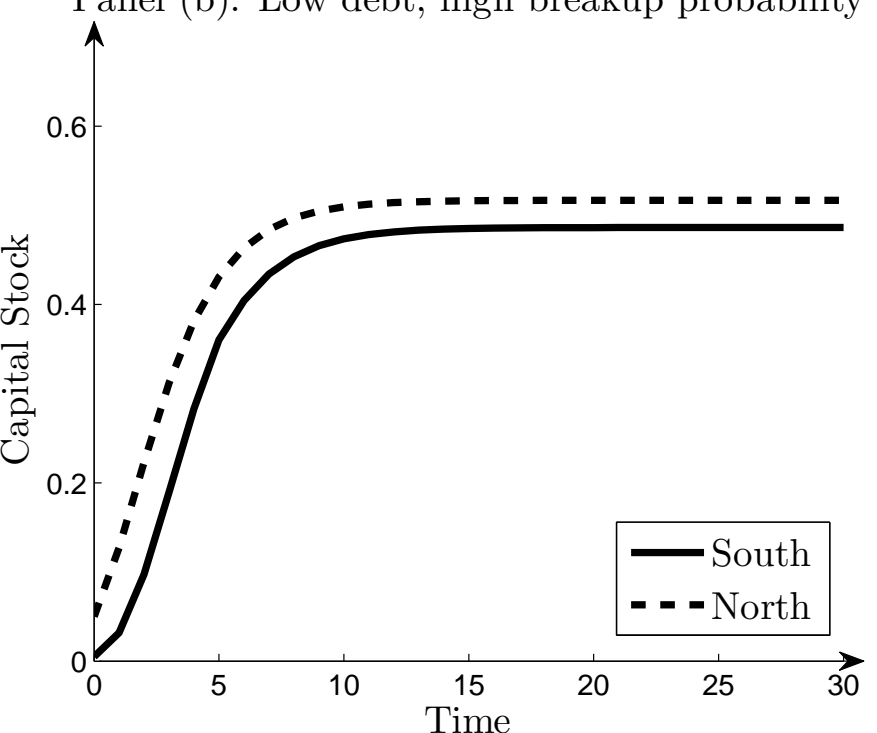

Panel (d): High debt, high breakup probability

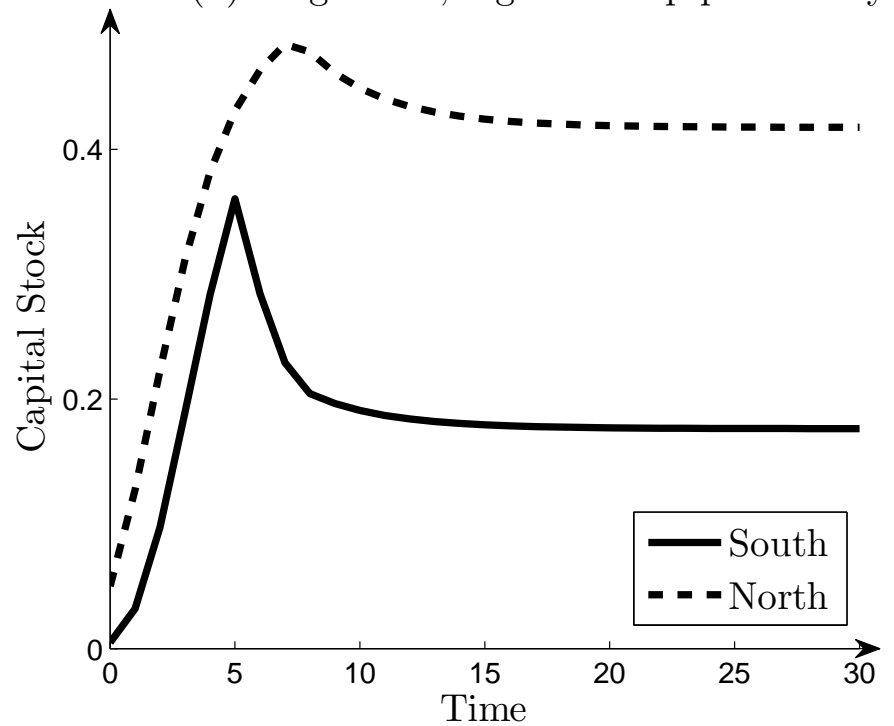

This figure shows the evolution of the capital stock for two countries (South and North) belonging to an economic union, under the assumption that South issues an amount of debt $d$ in period $t=6$. The solid line indicates the evolution of South's capital stock and the dotted line the evolution of North's capital stock. The different panels consider different parameter values for the breakup probability of the union and for the amount of debt issued by South. 